\title{
Asymmetric Capital Structure Adjustments: New Evidence from Dynamic Panel Threshold Models*
}

\author{
Viet Anh Dang`, Minjoo Kimªnd Yongcheol Shin ${ }^{\S}$
}

This version: March 2012

\begin{abstract}
We develop a dynamic panel threshold model of capital structure to test the dynamic trade-off theory, allowing for asymmetries in firms' adjustments toward target leverage. Our novel estimation approach is able to consistently estimate heterogeneous speeds of adjustment in different regimes as well as to properly test for the threshold effect. We consider several proxies for adjustment costs that affect the asymmetries in capital structure adjustments and find evidence that firms with large financing imbalance (or a deficit), large investment or low earnings volatility adjust faster than those with the opposite characteristics. Firms not only adjust at different rates but also seem to adjust toward heterogeneous leverage targets. Moreover, we document a consistent pattern that firms undertaking quick adjustment are over-levered with a financing deficit and rely heavily on equity issues to make such adjustment.
\end{abstract}

JEL Classification: C12, C33, G32.

Keywords: Capital Structure, Target Leverage, Dynamic Trade-off Theory, Dynamic Panel Threshold Model.

*We would like to thank two anonymous referees, Richard T. Baillie (the editor), session participants at the EFMA 2008 conference, seminar participants at Leeds University Business School (Economics and CASIF), Sung Kyun Kwan and Yonsei Universities, and especially Michael Brennan, Charlie Cai, Yoosoon Chang, Ian Garrett, David Hillier, Kevin Keasy, Joon Park, Krishna Paudyal, Kevin Reilly, Kasbi Salma, Myung Seo and Stephen Wilcox for helpful comments and suggestions. Partial financial support from the ESRC (Grant No. RES-000-22-3161) is gratefully acknowledged. The usual disclaimer applies.

${ }^{\dagger}$ Viet Anh Dang, Manchester Business School, Booth Street West, Manchester, M15 6PB, the UK. Email: Vietanh.Dang@mbs.ac.uk.

${ }^{\ddagger}$ Minjoo Kim, University of Glasgow, G12 8QQ, the UK. Email: Minjoo.Kim@glasgow.ac.uk.

$\S$ Yongcheol Shin, University of York, YO10 5DD, the UK. Email: yongcheol.shin@york.ac.uk. 


\section{Introduction}

Since Modigliani and Miller's (1958) irrelevance propositions, a number of theories have been developed to show that corporate capital structure does matter in the presence of capital market frictions and imperfections (e.g., corporate and personal taxes, costly financial distress/bankruptcy, agency problems and information asymmetries). As one of the most dominant views of capital structure, the trade-off theory focuses on two such frictions, namely taxes and financial distress costs, and argues that firms have optimal capital structure that balances the tax benefits of debt (i.e., debt interest tax shields) against the costs of financial distress/bankruptcy. ${ }^{1}$ The empirical implication follows that in a dynamic framework, corporate leverage should exhibit mean reversion as firms seek to undertake adjustment toward their target leverage. ${ }^{2}$ Hence, a large number of empirical studies have attempted to examine the validity of the trade-off theory by testing whether and how fast firms move toward target leverage.

Recent empirical research generally documents evidence in favor of firms' (meanreverting) adjustment toward target leverage, which is consistent with the trade-off theory. Estimating a linear partial adjustment model of leverage, Ozkan (2001) and Flannery and Rangan (2006) find that UK and US firms move toward their target leverage reasonably quickly; their adjustment speeds are estimated at above $50 \%$ and $30 \%$, respectively. Antoniou et al. (2008) estimate a similar dynamic model and provide cross-country evidence of capital structure adjustment for both market-based economies (the UK and the US) and bank-oriented economies (France, Germany and Japan). ${ }^{3}$ However, an important limitation of these studies is that they (implicitly) assume symmetry in the mechanism of adjustment such that firms adjust at the same rate toward homogeneous target leverage. Consequently, they do not allow for a possibility that firms facing differential adjustment costs may take different paths toward their optimal capital structures (e.g., Fischer et al., 1989; Leland, 1994).

Our paper aims to fill this gap in the literature by developing a novel empirical approach to testing the dynamic trade-off theory, allowing for asymmetric and costly adjustment toward leverage targets. In particular, we propose a dynamic panel threshold model of leverage, allowing for asymmetries in the mechanism of adjustment for firms in different 'refinancing regimes' associated with differential adjustment costs. To illustrate

\footnotetext{
${ }^{1}$ See Kraus and Litzenberger (1973), Brennan and Schwartz (1978) and Bradley et al. (1984) for early static trade-off models; Hennessy and Whited (2006), Strebulaev (2007) and Titman and Tsyplakov (2007) for recent dynamic trade-off models.

${ }^{2}$ There are alternative views of capital structure, such as the pecking order theory (Myers and Majluf, 1984; Myers, 1984), the market timing hypothesis (Baker and Wurgler, 2002) and the inertia hypothesis (Welch, 2004), which do not predict target leverage and adjustment toward such target. See Harris and Raviv (1991) and Frank and Goyal (2007) for comprehensive reviews of the capital structure literature.

${ }^{3}$ Most recent research disagrees about the magnitude of the estimated speed of adjustment, which is sensitive to the econometric procedures employed, especially in the presence of unobserved firm fixedeffects in short dynamic panels (e.g., Huang and Ritter, 2009).
} 
the advantage of our approach, consider a dynamic setting in which a firm faces different costs of leverage adjustment according to its characteristics and/or its position relative to target leverage. Rather than having a unique leverage target, the firm may have a target range within which it allows its leverage to vary. Capital structure adjustment is undertaken only when the costs of such adjustment are outweighed by the benefits of being close to target leverage (Fischer et al., 1989; Leary and Roberts, 2005). Importantly, the size and speed of the adjustment are dependent on the deviation of the actual leverage from the target (e.g., Byoun, 2008) and the costs of such adjustment, which in turn are affected by the degree of financial constraints and flexibility facing the firm (e.g., Flannery and Hankins, 2007; Faulkender et al., 2011). For example, firms with low earnings volatility enjoy a lower cost of capital than those with high volatility, thus suggesting they should undertake faster adjustment. In this dynamic framework, the conventional linear partial adjustment model adopted in the literature becomes misspecified while our proposed regime-switching dynamic panel model emerges as a more appropriate testing approach.

Our paper makes two major contributions to the literature. First, the dynamic panel threshold model of leverage developed in our paper is capable of directly testing the validity of the dynamic trade-off theory. A few recent empirical studies have examined the relations between the speed of capital structure adjustment and firm-specific and macroeconomic variables (e.g., Drobetz and Wanzenried, 2006; Drobetz et al., 2006) and the impact of financial constraints and/or financing gaps on the asymmetry in such adjustment (e.g., Flannery and Hankins, 2007; Byoun, 2008; Faulkender et al., 2011). This strand of research, however, does not focus on consistently estimating heterogeneous speeds of adjustment for firms facing differential adjustment costs. Our approach can consistently estimate heterogeneous adjustment speeds and provide important insights into the characteristics of firms that follow asymmetric adjustment paths. In addition, our model entertains a possibility that firms not only adjust at heterogeneous rates (i.e., short-run asymmetry) but also adjust toward heterogeneous leverage targets (i.e., longrun asymmetries). This is an important advantage over recent research that allows for the asymmetry in the adjustment speed but not in target leverage such that firms may only undertake asymmetric adjustment toward homogeneous target leverage (Byoun, 2008; Faulkender et al., 2011; Dang et al., 2011). Dynamic trade-off models generally imply the existence of target leverage ranges (Fischer et al., 1989; Leary and Roberts, 2005) so there is no clear justification as to why firms in different refinancing regimes should consider a homogeneous target.

Second, we develop econometric techniques that provide both consistent and efficient estimates of heterogeneous speeds of adjustment as well as a valid testing procedure for threshold effects in short dynamic panels with unobserved individual firm fixed-effects. Most recent studies adopt the sample-splitting or dummy variable approach to investigate 
the (asymmetric) dynamic trade-off behavior of firms with different characteristics (e.g., Flannery and Hankins, 2007; Byoun, 2008; Faulkender et al., 2011; Dang et al., 2011). However, this methodology is, at most, arbitrary and is likely to suffer from a sample selection bias problem (Hansen, 2000). Our proposed dynamic panel threshold model overcomes this limitation because in our framework, the threshold parameter is consistently estimated within the model rather than being imposed. Our estimation approach extends static panel threshold modeling (Hansen, 1999) by combining the existing timeseries techniques on threshold models (Chan, 1993; Hansen, 2000) and advanced methods for dynamic panels (Alvarez and Arellano, 2003). Specifically, it involves generalizing the Anderson and Hsiao (1982) instrumental-variable estimator (hereafter AH-IV) and, most importantly, the Arellano and Bond (1991) generalized methods of moments estimator (hereafter GMM) to a new estimation approach applicable for dynamic panel threshold models. To test for the threshold effect, we follow Andrews and Ploberger (1994) and Hansen $(1996,1999,2000)$ and develop a bootstrap-based testing procedure, the validity of which is then supported by Monte Carlo simulation studies. Further, our approach, based on one-stage estimation is free of generated regressors problems inherent in the two-stage procedure in which target leverage is estimated in the first stage before the speed of adjustment is estimated in the second, an approach commonly used in recent studies (Byoun, 2008; Faulkender et al., 2011; Dang et al., 2011).

We consider several firm-specific variables that potentially affect the costs of capital structure adjustment, namely financing (cash flow) imbalance, growth opportunities, investment (capital expenditures), profitability, firm size and earnings volatility. Using an unbalanced panel of UK firms over the period 1996-2003, we first document that UK firms adjust relatively fast toward target leverage. Importantly, we find some evidence of short-run and long-run asymmetries in firms' adjustment mechanisms. The speed of adjustment is statistically different conditional on financing imbalance, firm investment or earnings volatility (i.e., short-run asymmetry) but not on the remaining regime-switching variables such as profitability and firm size. Specifically, firms with large financing imbalance (or a deficit), large investment or low earnings volatility have a significantly faster adjustment speed than those with the opposite characteristics. Further, we provide new evidence that not only do these firms adjust at different rates but they also seem to adjust toward heterogeneous leverage targets (i.e., long-run asymmetries). We observe several important characteristics of firms that have a faster speed of adjustment: they are significantly over-levered with a financing deficit and a considerably large deviation from target leverage, toward which they revert mainly through equity issues, rather than debt retirements. This finding suggests that firms tend to make quicker adjustment to avoid the potentially large financial distress costs caused by having above-target leverage. Taken together, our results are generally consistent with dynamic trade-off models of capital structure. 
The remainder of the paper is organized as follows. Section 2 provides a review of the (linear) partial adjustment model of leverage widely used in the literature and then develops a threshold (non-linear) partial adjustment model specification. Section 3 discusses the potential determinants of the speed of adjustment to be employed as the transition variable under the proposed regime-switching framework. Section 4 describes the estimation and testing procedures. Section 5 summarizes the data and sample, and discusses the empirical results. Section 6 concludes.

\section{Dynamic Capital Structure Adjustment Models}

The conventional econometric specification to model firms' adjustment toward target leverage takes the form of a partial adjustment process (e.g., Flannery and Rangan, 2006):

$$
\Delta \ell_{i t}=\delta\left(\ell_{i t}^{*}-\ell_{i, t-1}\right)+v_{i t}
$$

where $\ell_{i t}$ and $\ell_{i t}^{*}$ denote the actual (observed) and target leverage ratios for firm $i$ at time $t$, respectively. $v_{i t}$ is an error component, the details of which will be specified later. $\delta$ is the speed of adjustment that measures how fast firms move toward their target leverage. This coefficient is expected to lie between 0 and 1 , with a higher value indicating a faster speed of adjustment. ${ }^{4}$

There are two approaches to dealing with the unobserved target leverage in (1). First, target leverage can be proxied by the mean or the moving average of the actual (observed) leverage. The drawback of this approach lies in the difficulty to justify why target leverage should remain constant over time or only depend on past leverage decisions (ShyamSunder and Myers, 1999).

Second, target leverage can be considered as a unique ratio determined by firms' characteristics as follows:

$$
\ell_{i t}^{*}=\boldsymbol{\beta}^{\prime} \mathbf{x}_{i t}
$$

where $\mathbf{x}_{i t}$ denotes the $k \times 1$ vector of exogenous factors determining target leverage with $\beta$ being the structural parameters. Here, we follow the literature and consider the five most commonly-used determinants of leverage, namely (asset) tangibility, growth opportunities, non-debt tax shields, profitability and firm size (e.g., Rajan and Zingales,

\footnotetext{
${ }^{4}$ Recent research considers alternative specifications. For example, Lemmon et al. (2008) employ the initial leverage, $\ell_{i, 0}$ instead of $\ell_{i, t-1}$. Alternatively, Huang and Ritter (2009) use the long-differencing estimator based on the following equation:

$$
\ell_{i t}-\ell_{i, t-k}=\delta\left(\ell_{i t}^{*}-\ell_{i, t-k}\right)+v_{i t}, k>1,
$$

which alleviates the problem of weak instruments and relies on a smaller set of moment conditions, so that its small-sample performance is arguably more reliable than the standard GMM estimators (Hahn et al., 2007).
} 
1995; Ozkan, 2001; Lemmon et al., 2008).

In estimating (1) together with (2), there are two approaches available. The first is a two-stage procedure (Shyam-Sunder and Myers, 1999; Fama and French, 2002; Byoun, 2008 ), in which one regresses actual leverage on the firm-specific characteristics in (2), obtains the fitted values $\hat{\ell}_{i t}^{*}=\hat{\boldsymbol{\beta}}^{\prime} \mathbf{x}_{i t}$ (with $\hat{\boldsymbol{\beta}}$ being the consistent estimate of $\boldsymbol{\beta}$ ) and then uses this proxy for target leverage, $\ell_{i t}^{*}$, in (1). The most important limitation of this estimation approach is that it suffers from a generated regressors problem (Pagan, 1984), in which inference in the second-stage regression is likely to be invalid. ${ }^{5}$ This becomes potentially more problematic in dynamic threshold models where it can affect both estimation and testing of threshold effects and the speeds of adjustment. For this reason, the two-stage procedure is not employed in this paper and we now turn to an alternative approach, namely, the one-stage procedure (Ozkan, 2001; Flannery and Rangan, 2006), in which $(2)$ is substituted into (1) to yield: ${ }^{6}$

$$
\ell_{i t}=\phi \ell_{i, t-1}+\boldsymbol{\pi}^{\prime} \mathbf{x}_{i t}+v_{i t}
$$

where $\phi=1-\delta$ and $\boldsymbol{\pi}=\delta \boldsymbol{\beta}$. Here, we follow the literature (e.g., Ozkan, 2001) and model $v_{i t}$ as an one-way error component that includes the individual firm fixed effects, as follows:

$$
v_{i t}=\alpha_{i}+e_{i t}
$$

The firm fixed effects, $\alpha_{i}$, may capture (unobserved) firm-specific characteristics such as managerial ability and skills, the level of competition in the industry and the life cycle of products. $e_{i t}$ is the well-behaved error term with a zero mean and constant variance. Note that by using (3), both the short-run dynamics, $\hat{\phi}$, and the long-run coefficients, $\hat{\boldsymbol{\beta}}=\frac{\hat{\pi}}{1-\hat{\phi}}$, can be jointly estimated in one stage. Hence, this approach does not suffer from the generated regressors problem that affects estimation precision and inference of the aforementioned two-stage approach.

Testing trade-off models using (3) assumes that firms undertake capital structure adjustments in a symmetric fashion. In the presence of costly adjustment, however, this assumption is no longer valid because leverage changes are infrequent and tend to occur at 'restructuring points' (Fischer et al., 1989; Leary and Roberts, 2005; Titman and Tsyplakov, 2007). Firms adjust at different rates according to the position of their actual leverage relative to targets as well as the costs of their adjustment (e.g., Byoun, 2008; Faulkender et al., 2011). To capture this dynamic trade-off behavior, we develop the regime-switching, dynamic threshold model: ${ }^{7}$

\footnotetext{
${ }^{5}$ Previous research estimating the partial adjustment model in two stages has largely ignored this issue (e.g., Fama and French, 2002; Byoun, 2008).

${ }^{6}$ We would like to thank an anonymous reviewer for this important suggestion.

${ }^{7}$ Alternatively, one can adopt the two-stage estimation procedure outlined above and estimates the
} 


$$
\ell_{i t}=\left(\phi_{1} \ell_{i, t-1}+\boldsymbol{\pi}_{1}^{\prime} \mathbf{x}_{i t}\right) 1_{\left\{q_{i t} \leq c\right\}}+\left(\phi_{2} \ell_{i, t-1}+\boldsymbol{\pi}_{2}^{\prime} \mathbf{x}_{i t}\right) 1_{\left\{q_{i t} \leq c\right\}}+v_{i t},
$$

where $1_{\{\cdot\}}$ is an indicator function taking the value 1 if the event is true and 0 otherwise. Model (4) represents an important extension of the (linear) partial adjustment model, (3) in that it allows for short-run asymmetries in two $\operatorname{AR}(1)$ parameters $\left(\phi_{1}\right.$ and $\left.\phi_{2}\right)$, the implied speeds of adjustment $\left(\delta_{1}=1-\phi_{1}\right.$ and $\left.\delta_{2}=1-\phi_{2}\right)$, and the short run coefficients $\left(\boldsymbol{\pi}_{1}\right.$ and $\left.\boldsymbol{\pi}_{2}\right)$ as well as long-run asymmetries in the target leverage relationships $\left(\boldsymbol{\beta}_{\mathbf{1}}\right.$ and $\boldsymbol{\beta}_{\mathbf{2}}$ ), conditional on the (regime-switching) transition variable, $q_{i t}$, and the threshold parameter, $c$. For simplicity, the transition variable, $q_{i t}$, is assumed to be stationary and exogenous.

The threshold partial adjustment model given by (4) has at least four advantages over the simple sample-splitting or dummy variable (two-stage) approaches to examining asymmetries in dynamic capital structure adjustments (Byoun, 2008; Faulkender et al., 2011; Dang et al., 2011). First, the exogenous sample-splitting method requires an arbitrary choice of known threshold a priori, such as the median, quartiles or quintiles. ${ }^{8}$ Our proposed approach overcomes this limitation because it allows the threshold parameter to be estimated within the model. Second, unlike the approach using dummies or sub-samples where firms are typically classified into a regime over the entire sample period, our model allows firms to switch regime over-time conditional on the proxies for adjustment costs. Finally, unlike the two-stage approach commonly used in recent research (Byoun, 2008; Faulkender et al., 2011; Dang et al., 2011), our one-stage estimation approach based on (4) does not suffer from the generated regressors problem and the resulting estimation and inference complexities, especially in dynamic panels. Finally, our one-stage approach allows for complex adjustment mechanisms whereby firms may not only adjust at heterogeneous rates (short-run asymmetry) but also adjust toward heterogeneous leverage targets (long-run asymmetries). This is an important advantage over the two-stage procedure that implicitly imposes homogeneous target leverage relations (long-run symmetries). Thus, our approach can entertain several intermediate scenarios

following dynamic threshold model in the second stage:

$$
\Delta \ell_{i t}=\delta_{1}\left(\hat{\ell}_{i t}^{*}-\ell_{i t-1}\right) 1_{\left\{q_{i t} \leq c\right\}}+\delta_{2}\left(\hat{\ell}_{i t}^{*}-\ell_{i t-1}\right) 1_{\left\{q_{i t}>c\right\}}+w_{i t}, i=1, \ldots, N ; t=2, \ldots, T .
$$

where $\hat{\ell}_{i t}^{*}$ is estimated from:

$$
\ell_{i t}=\ell_{i t}^{*}+u_{i t}=\boldsymbol{\beta}^{\prime} \mathbf{x}_{i t}+u_{i t} .
$$

However, as in the linear model, this approach suffers from the generated regressors problem in a complex manner, unless the strong assumption of independence between the errors, $w_{i t}$ and $u_{i t}$ is maintained. Further, this approach also imposes the restriction of long-run symmetries such that the long-run relations between target leverage and its determinants remain the same even when firms are in different regimes.

${ }^{8}$ For example, Byoun (2008) uses dummy variables to distinguish between firms having a financing surplus or a deficit and/or above- or below- target leverage. This clearly involves a certain degree of arbitrariness since the threshold parameters are imposed instead of being consistently estimated within the model. 
from symmetries in target leverage relations and the speed of adjustment to asymmetries in both in a flexible manner.

\section{Determinants of the Speed of Capital Structure Adjustment}

In this section, we examine a number of candidates for the transition variable, $q$, in our regime-switching framework, (4). While a large body of capital structure research investigates the explanatory power of firm-specific or macro-economic factors determining target leverage (see Frank and Goyal (2007) for a review), the literature is relatively silent on the potential determinants of the speed of leverage adjustment. Our discussion is motivated by a few of recent empirical studies on costly adjustment (e.g., Leary and Roberts, 2005; Drobetz et al., 2006; Flannery and Hankins, 2007; Byoun, 2008; Faulkender et al., 2011; Dang et al., 2011).

In adjusting leverage toward the target, firms have the following options. They can issue new debt and/or repurchase existing shares when they have above-target leverage; they can issue new equity and/or retire debt when they have below-target leverage (e.g., Flannery and Hankins, 2007). In addition, firms can make leverage adjustment internally by keeping profits as retained earnings or pay out as dividends. Overall, the speed with which firms adjust leverage is determined by the adjustment costs, financial flexibility and constraints that they face. In what follows, we turn to discuss the (asymmetric) mechanisms in which these factors affect the speed of leverage adjustment.

\section{Financing imbalance (deficit/surplus)}

Firms that have to cover substantial cash flow deficits or surpluses by changing their debt and equity mix may face potentially lower costs of leverage adjustment because a proportion of the adjustment costs is 'shared' with transaction costs (Faulkender et al., 2011). ${ }^{9}$ These firms are thus expected to have a quick speed of adjustment. The sign of the financing imbalance also has important implications for firms' adjustment speeds (Dang et al., 2011). Specifically, when firms have a financing deficit, they are under considerable pressure to offset this deficit by issuing debt, equity or both securities. Yet, such external financing activities may provide an opportunity for these firms to choose an appropriate debt-equity mix to move toward their target leverage. On the other hand, when firms have a cash flow surplus, they are under relatively less pressure to address this imbalance, implying less incentive for them to undertake leverage adjustment. However, these firms

\footnotetext{
${ }^{9}$ A firm's financing (cash flow) deficit or surplus can be calculated as dividend payments plus net investment and changes in working capital less operating cash flows after interest and taxes (ShyamSunder and Myers, 1999). See also Table 2.
} 
may find it easier to adjust toward target leverage because the costs of retiring debt and/or repurchasing equity (in the presence of a deficit) may be lower than the costs of issuing those securities (in the presence of a surplus). Since the above two predictions are conflicting, the relation between firms' financing imbalance and the speed of adjustment will be resolved empirically.

\section{Growth opportunities}

The impact of growth opportunities on firms' adjustment speeds is theoretically ambiguous. First, high-growth firms are likely to be young and adopt a low-leverage policy to control the under-investment problem (Myers, 1977). They may also have low profitability and limited internal funds, and rely heavily on external (equity) financing to fund growth opportunities. Through frequent visits to the external capital markets, these firms can adjust leverage more easily by appropriately altering the mix of debt and equity (Drobetz et al., 2006). Low-growth firms, on the other hand, tend to rely more on internal finance, so any capital structure changes are likely to take the form of internal adjustment, the scope and magnitude of which is limited by the size of internal funds. Hence, the speed of adjustment is expected to be relatively faster for high-growth firms than for their low-growth counterparts. However, an opposite prediction can be made. Many low-growth firms are mature, cash-rich and highly profitable so that they may maintain a high-leverage policy to mitigate the free cash flow problem (Jensen, 1986). While low-growth firms do not rely on external (equity) financing as much as high-growth firms, they face less severe asymmetric information and agency problems, making it less costly to adjust toward target leverage. Further, low-growth firms with typically high leverage may find it more beneficial to quickly revert to target leverage in order to avoid potentially high financial distress and bankruptcy costs.

\section{Investment}

Corporate investments have important effects on both financing decisions (Lang et al., 1996) and adjustment toward optimal capital structure (Flannery and Hankins, 2007) because capital expenditures tend to be mainly funded by internally generated cash flow (Myers, 1984). As a result, high-growth firms with new investments financed with internal funds may have less scope left for (internal) capital structure adjustments (e.g., dividend payments, debt retirements or equity repurchases), implying a slower speed of adjustment for these firms. However, it can be also argued that firms facing large investment opportunities may resort to external finance, which may present them with an opportunity to change their capital structure mix appropriately given that the cost of adjustment can be 'shared' with the cost of raising external funds (Faulkender et al., 2011). 


\section{Profitability}

Profitable firms are likely to have available retained earnings so they may not suffer from severe (internal) financial constraints and be able to issue securities at a low cost. In addition, these firms have incentive to take advantage of debt interest tax shields and minimize the asset substitution effect, especially when they are under-levered. ${ }^{10}$ Taken together, firms with high profitability are likely to enjoy financial flexibility and adjustment benefits, and, thus, are able to make quicker adjustment toward target leverage. On the other hand, firms with low profitability tend to have limited internal funds and consequently face financial instability and (internal) constraints, which prevent them from making rapid leverage adjustment. This suggests that profitability has a positive effect on the speed of adjustment. However, an opposite prediction can be made. Less profitable firms are typically highly levered, as predicted by the pecking order theory (Myers and Majluf, 1984) or dynamic trade-off models (e.g., Strebulaev, 2007), as well as suggested by previous empirical results in the literature (e.g., Titman and Wessels, 1988; Rajan and Zingales, 1995). Since high leverage may result in potentially large financial distress costs, firms with low profitability should have more incentive to revert to their target leverage quickly, implying a negative impact of profitability on the speed of adjustment.

\section{Size}

Capital structure adjustments generally involve substantial transaction costs (e.g., brokerage fees for new issues), of which the fixed component is relatively smaller for large firms. Further, large firms are typically mature with high tangibility, profitability and financial flexibility, implying less severe asymmetric information, adverse selection and moral hazard problems, as well as better access to capital markets. Hence, the cost of external financing is smaller for large firms, suggesting a quicker speed of adjustment for them (Drobetz and Wanzenried, 2006). On the other hand, large firms tend to use public debt that is more expensive to adjust, while they have less cash flow volatility, lower financial distress costs and fewer debt covenants. Thus, they have less incentive and external pressure to adjust capital structure, implying a slower adjustment speed for large firms (Flannery and Rangan, 2006).

\section{Volatility}

Under the trade-off framework, firms with volatile earnings have difficulty borrowing because in bad states of the world, they may generate low earnings that are insufficient for them to meet debt obligations (Antoniou et al., 2008). Put it differently, firms with

\footnotetext{
${ }^{10}$ For under-levered firms, retained profits increase the value of equity, resulting in a lower leverage ratio and further deviation from target leverage, implying greater incentive for these firms to revert toward the target.
} 
high earnings volatility may have limited access to the capital markets to make capital structure adjustments. The implication follows that earnings volatility and the speed of adjustment are inversely related.

\section{Econometric Methodology}

\subsection{Threshold Partial Adjustment Models}

In this subsection, we derive the GMM estimators and describe how the threshold parameter is estimated and its confidence intervals are constructed. The fixed-effects (hereafter FE) estimates of $\phi_{1}$ and $\phi_{2}$ in (4) are biased downward because the regressors are correlated with the (unobserved) firm fixed effects, $\alpha_{i}$, via the correlation between $\ell_{i, t-1}$ and $v_{i t}$, i.e., $\mathbf{E}\left[\ell_{i, t-1} v_{i t}\right] \neq 0$ (Nickell, 1981). This suggests that the FE estimator of the speeds of adjustment, $\delta_{1}=1-\phi_{1}$ and $\delta_{2}=1-\phi_{2}$, is biased upward. Note that the FE estimator of $\boldsymbol{\pi}_{1}$ and $\boldsymbol{\pi}_{2}$ are also biased.

To address this issue, we follow the literature and consider using instrumental variable estimators and, more importantly, GMM. Despite a large literature on GMM in linear dynamic panels (e.g., Arellano and Bond, 1991; Arellano and Bover, 1995; Blundell and Bond, 1998), there has been no rigorous research investigating threshold mechanisms in dynamic panel models. Here, we extend Hansen's (1999) estimation and inference theory for static panel threshold models and propose a new estimation and testing procedure for the dynamic case. Specifically, we combine time series techniques on threshold modeling (Chan, 1993; Hansen, 2000; Caner and Hansen, 2004) with the existing GMM literature (Alvarez and Arellano, 2003).

We first rewrite (4) as:

$$
\ell_{i t}=\left\{\phi_{1} \ell_{1 i, t-1}(c)+\boldsymbol{\pi}_{1}^{\prime} \mathbf{x}_{1 i t}(c)\right\}+\left\{\phi_{2} \ell_{2 i, t-1}(c)+\boldsymbol{\pi}_{2}^{\prime} \mathbf{x}_{2 i t}(c)\right\}+v_{i t}, v_{i t}=\alpha_{i}+e_{i t},
$$

where $\ell_{1 i, t-1}(c)=\ell_{i, t-1} 1_{\left\{q_{i t} \leq c\right\}}, \ell_{2 i, t-1}(c)=\ell_{i, t-1} 1_{\left\{q_{i t}>c\right\}}, \mathbf{x}_{1 i t}(c)=\mathbf{x}_{i t} 1_{\left\{q_{i t} \leq c\right\}}$ and $\mathbf{x}_{2 i t}(c)=$ $\mathbf{x}_{i t} 1_{\left\{q_{i t}>c\right\}}$. Next, to deal with the correlation between the regressors and the firm fixed effects in (4), we use the first-difference transformation of (5):

$\Delta \ell_{i t}=\left\{\phi_{1} \Delta \ell_{1 i, t-1}(c)+\boldsymbol{\pi}_{1}^{\prime} \Delta \mathbf{x}_{1 i t}(c)\right\}+\left\{\phi_{2} \Delta \ell_{2 i, t-1}(c)+\boldsymbol{\pi}_{2}^{\prime} \Delta \mathbf{x}_{2 i t}(c)\right\}+\Delta e_{i t}, i=1, \ldots, N ; t=2, \ldots, T$,

which is free of the fixed effects $\alpha_{i}$. However, applying the pooled OLS estimator to (6) still produces biased estimates since $\Delta \ell_{1 i, t-1}(c)$ and $\Delta \ell_{2 i, t-1}(c)$ are correlated with $\Delta e_{i t}$. Hence, we need to find instruments for $\Delta \ell_{1 i, t-1}(c)$ and $\Delta \ell_{2 i, t-1}(c)$ that satisfy the orthogonal condition with $\Delta e_{i t}$. Two obvious candidates for these instruments are $\ell_{1 i, t-2}(c)$ and $\ell_{2 i, t-2}(c)$, as commonly used in the (just-identified) instrumental variable 
estimation approach (hereafter AH-IV) (Anderson and Hsiao, 1982). ${ }^{11}$

To improve the efficiency of the AH-IV estimator, we follow Arellano and Bond (1991) and consider lagged values of $\ell_{1 i, t-2}(c)$ and $\ell_{2 i, t-2}(c)$ as additional instruments for $\Delta \ell_{1 i, t-1}(c)$ and $\Delta \ell_{2 i, t-1}(c)$ in (6). We next construct the full GMM instrument matrices for $\Delta \ell_{1 i, t-1}(c)$ and $\Delta \ell_{2 i, t-1}(c)$, denoted $\mathbf{W}_{1 i}(c)$ and $\mathbf{W}_{2 i}(c)$, respectively for $i=1, \ldots, N$ and $j=1,2$ :

$$
\mathbf{W}_{j i}(c)=\left[\begin{array}{cccc}
\ell_{j i 1}(c) & 0 & \cdots & 0 \\
0 & \ell_{j i 1}(c), \ell_{j i 2}(c) & \cdots & 0 \\
\vdots & \vdots & \ddots & \vdots \\
0 & 0 & \cdots & \ell_{j i 1}(c), \ell_{j i 2}(c), \cdots, \ell_{j i, T-2}(c)
\end{array}\right] .
$$

We express (6) in the matrix form as follows:

$$
\Delta \boldsymbol{\ell}=\mathbf{Z}_{1}(c) \boldsymbol{\theta}_{1}+\mathbf{Z}_{2}(c) \boldsymbol{\theta}_{2}+\Delta \mathbf{e}=\mathbf{Z}(\boldsymbol{c}) \boldsymbol{\theta}+\Delta \mathbf{e},
$$

where $\mathbf{Z}_{1}(c)=\left(\Delta \boldsymbol{\ell}_{1,-1}(c), \Delta \mathbf{X}_{1}(c)\right), \mathbf{Z}_{2}(c)=\left(\Delta \boldsymbol{\ell}_{2,-1}(c), \Delta \mathbf{X}_{2}(c)\right), \mathbf{Z}(c)=\left(\mathbf{Z}_{1}(c), \mathbf{Z}_{2}(c)\right)$, $\boldsymbol{\theta}_{1}=\left(\phi_{1}, \boldsymbol{\pi}_{1}^{\prime}\right)^{\prime}, \boldsymbol{\theta}_{2}=\left(\phi_{2}, \boldsymbol{\pi}_{2}^{\prime}\right)^{\prime}, \boldsymbol{\theta}=\left(\boldsymbol{\theta}_{1}^{\prime}, \boldsymbol{\theta}_{2}^{\prime}\right)^{\prime}, \Delta \boldsymbol{\ell}=\left(\Delta \boldsymbol{\ell}_{1}^{\prime}, \ldots, \Delta \boldsymbol{\ell}_{N}^{\prime}\right)^{\prime}, \Delta \boldsymbol{\ell}_{i}=\left(\Delta \ell_{i 2}, \ldots, \Delta \ell_{i T}\right)^{\prime}$, $\Delta \boldsymbol{\ell}_{j,-1}(c)=\left(\Delta \boldsymbol{\ell}_{j 1,-1}^{\prime}(c), \ldots, \Delta \boldsymbol{\ell}_{j N,-1}^{\prime}(c)\right)^{\prime}, \Delta \boldsymbol{\ell}_{j i,-1}(c)=\left(\Delta \ell_{j i 1}(c), \ldots, \Delta \ell_{j i, T-1}(c)\right)^{\prime}, \Delta \mathbf{X}_{j}(c)=$ $\left(\Delta \mathbf{X}_{j 1}^{\prime}(c), \ldots, \Delta \mathbf{X}_{j N}^{\prime}(c)\right)^{\prime}$, and $\Delta \mathbf{X}_{j i}(c)=\left(\Delta \mathbf{x}_{j i 2}(c), \ldots, \Delta \mathbf{x}_{j i T}(c)\right)^{\prime}$ for $j=1,2$.

Under the maintained assumption that the $K \times 1$ vector of covariates, $\mathbf{x}_{i t}$, is exogenous with respect to $e_{i t}$, we can construct the associated instrument matrix for $\mathbf{Z}(c)$ in (8) as the following $N(T-2) \times\{(T-2)(T-1)+2 K\}$ matrix: $^{12}$

$$
\mathbf{W}(c)=\left[\begin{array}{c}
\mathbf{W}_{1}(c) \\
\vdots \\
\mathbf{W}_{N}(c)
\end{array}\right], \mathbf{W}_{i}(c)=\left(\mathbf{W}_{1 i}(c), \Delta \mathbf{X}_{1 i}(c), \mathbf{W}_{2 i}(c), \Delta \mathbf{X}_{2 i}(c)\right), i=1, \ldots, N .
$$

By employing the moment conditions, $\mathbf{E}\left[\mathbf{W}(c)^{\prime} \Delta \mathbf{e}\right]=\mathbf{0}$ with $\Delta \mathbf{e}=\left(\Delta \mathbf{e}_{1}^{\prime}, \ldots, \Delta \mathbf{e}_{N}^{\prime}\right)^{\prime}$ and $\Delta \mathbf{e}_{i}=\left(\Delta e_{i 3}, \ldots, \Delta e_{i T}\right)^{\prime}$, we obtain a GMM estimator of $\boldsymbol{\theta}$ (given a threshold parameter value, c) as:

$$
\hat{\boldsymbol{\theta}}(c)=\left[\mathbf{Z}(c)^{\prime} \mathbf{W}(c) \mathbf{V}(c)^{-1} \mathbf{W}(c)^{\prime} \mathbf{Z}(c)\right]^{-1}\left[\mathbf{Z}(c)^{\prime} \mathbf{W}(c) \mathbf{V}(c)^{-1} \mathbf{W}(c)^{\prime} \Delta \boldsymbol{\ell}\right]
$$

The standard GMM theory suggests that an optimal (inverted) weighting matrix, denoted

\footnotetext{
${ }^{11}$ Note that the correlation between $\Delta \ell_{1 i, t-1}(c)$ and $\Delta \ell_{2 i, t-1}(c)$ is most likely to be negligible as the transition probability from one regime to the other can be relatively small. More importantly, the level instruments, $\ell_{1 i, t-1}(c)$ and $\ell_{2 i, t-1}(c)$, are orthogonal. Hence, there are no restrictions imposed on the correlation structure within the instruments.

${ }^{12}$ In the case where $\boldsymbol{x}_{i t}$ 's are weakly or strictly exogenous, one can in theory use $\left(\mathbf{x}_{i 1}, \ldots, \mathbf{x}_{i T}\right)$ or $\left(\mathbf{x}_{i 1}, \ldots, \mathbf{x}_{i t-1}\right)$ as additional instruments. In our empirical analysis, we do not consider these instruments to avoid the over-fitting bias problem.
} 
$\mathbf{V}(c)$, be given by the covariance matrix of the orthogonality conditions, $\mathbf{E}\left[\mathbf{W}(c)^{\prime} \Delta \mathbf{e}\right]=$ 0 .

Next, we derive the GMM estimator in two cases, with homoscedasticity or heteroscedasticity, respectively. First, if $e_{i t}$ is independent and has homoscedastic variance, $\sigma^{2}$, across firms and over time, the GMM estimator can be simply computed in one step (Arellano and Bond, 1991). The covariance matrix of $\mathbf{E}\left[\mathbf{W}(c)^{\prime} \Delta \mathbf{e}\right]=\mathbf{0}$ is given by:

$$
\mathbf{E}\left[\mathbf{W}_{i}(c)^{\prime} \Delta \mathbf{e}_{i} \Delta \mathbf{e}_{i}^{\prime} \mathbf{W}_{i}(c)\right]=\sigma^{2} \mathbf{W}_{i}(c)^{\prime} \mathbf{G} \mathbf{W}_{i}(c),
$$

where $\mathbf{G}$ is a $(T-2) \times(T-2)$ fixed matrix with 2's on the main diagonal, -1 's on the next sub-diagonals, and zeros otherwise. Thus, we obtain the one-step GMM estimator by:

$\hat{\boldsymbol{\theta}}_{G M M_{1}}(c)=\left[\mathbf{Z}(c)^{\prime} \mathbf{W}(c) \hat{\mathbf{V}}_{G M M_{1}}(c)^{-1} \mathbf{W}(c)^{\prime} \mathbf{Z}(c)\right]^{-1}\left[\mathbf{Z}(c)^{\prime} \mathbf{W}(c) \hat{\mathbf{V}}_{G M M_{1}}(c)^{-1} \mathbf{W}(c)^{\prime} \Delta \boldsymbol{\ell}\right]$

where $\hat{\mathbf{V}}_{G M M_{1}}(c)=\sum_{i=1}^{N} \mathbf{W}_{i}(c)^{\prime} \mathbf{G} \mathbf{W}_{i}(c)$.

If $e_{i t}$ is heteroscedastic, however, the one-step GMM estimator outlined above is inefficient (Arellano and Bond, 1991). In this more general case, we consider the following robust estimator of the covariance matrix (Arellano, 2003, p.89):

$$
\hat{\mathbf{V}}_{G M M_{2}}(c)=\sum_{i=1}^{N} \mathbf{W}_{i}(c)^{\prime} \Delta \hat{\mathbf{e}}_{i}(c) \Delta \hat{\mathbf{e}}_{i}(c)^{\prime} \mathbf{W}_{i}(c)
$$

where $\Delta \hat{\mathbf{e}}_{i}(c)=\Delta \boldsymbol{\ell}_{i}-\mathbf{Z}_{i}(c) \hat{\boldsymbol{\theta}}_{G M M_{1}}(c)$ is the $(T-2) \times 1$ vector of residuals obtained from the one-step GMM estimation. We then obtain an efficient two-step GMM estimator by: ${ }^{13}$

$$
\hat{\boldsymbol{\theta}}_{G M M_{2}}(c)=\left[\mathbf{Z}(c)^{\prime} \mathbf{W}(c) \hat{\mathbf{V}}_{G M M_{2}}(c)^{-1} \mathbf{W}(c)^{\prime} \mathbf{Z}(c)\right]^{-1}\left[\mathbf{Z}(c)^{\prime} \mathbf{W}(c) \hat{\mathbf{V}}_{G M M_{2}}(c)^{-1} \mathbf{W}(c)^{\prime} \Delta \boldsymbol{\ell}\right]
$$

Next, the threshold parameter, $c$, can be consistently estimated as follows:

$$
\hat{c}=\underset{c \in \mathcal{C}}{\operatorname{argmin}} Q(c),
$$

\footnotetext{
${ }^{13}$ In principle, we may consider iterated or continuously updated GMM estimators as follows. First, we obtain the updated weighting matrix, $\hat{\mathbf{V}}_{G M M}^{u}(c)$, in (13) by using the updated residuals, $\Delta \hat{\mathbf{e}}_{i}^{u}(c)=$ $\Delta \boldsymbol{\ell}_{i}-\mathbf{Z}_{i}(c) \hat{\boldsymbol{\theta}}_{G M M_{2}}(c)$. Then, we obtain $\hat{\boldsymbol{\theta}}_{G M M}^{u}(c)$ by substituting $\hat{\mathbf{V}}_{G M M}^{u}(c)$ into (14). This iterative procedure will continue until convergence, and in theory should be more efficient. In our empirical analysis, we find that the difference between $\hat{\boldsymbol{\theta}}_{G M M_{2}}$ and the iterative estimator is mostly negligible, mainly because we only employ linear moment conditions. Hence, to save computation time, we focus on reporting the results based on $\hat{\boldsymbol{\theta}}_{G M M_{2}}$. Of course, when employing additional (nonlinear) moment conditions as suggested by Ahn and Schmidt $(1995,1997)$, the iterative estimator will be likely to produce more efficient results, though such extensions are beyond the scope of the paper both theoretically and computationally. We thank a reviewer for this suggestion.
} 
where $\mathcal{C}$ is the grid set and $Q(c)$ is the generalized distance measure, given by:

$$
Q(c)=\left\{\frac{1}{N} \mathbf{W}(c)^{\prime} \Delta \hat{\mathbf{e}}(c)\right\}^{\prime}\left\{\frac{1}{N} \hat{\mathbf{V}}_{G M M_{2}}(c)\right\}^{-1}\left\{\frac{1}{N} \mathbf{W}(c)^{\prime} \Delta \hat{\mathbf{e}}(c)\right\}
$$

where $\Delta \hat{\mathbf{e}}(c)=\Delta \boldsymbol{\ell}-\mathbf{Z}(c) \hat{\boldsymbol{\theta}}_{G M M_{2}}(c)$. Since the model is linear in $\boldsymbol{\theta}$ for each $c$, we use a practical grid search algorithm to find a consistent threshold estimate, $\hat{c}$, over a grid set that consists of the support of the transition variable, $q$. Following the literature, we use two cut-off points at the 15 th and 85 th percentiles to avoid potential extreme values of the transition variable while ensuring there is a sufficient number of observations in each regime.

Chan (1993) shows that under the assumption of exogenous transition variables, the threshold estimate, $\hat{c}$, is super-consistent, though its asymptotic distribution is complex and depends on nuisance parameters, which is not useful for inference in practice. Hansen (2000) suggests to construct a confidence interval for $c$ by forming a non-rejection region using the $L R$ statistic. Under the assumption that $\lambda_{n}=\theta_{2}-\theta_{1}=b N^{-\eta}$ with $b \neq 0$ and $0<\eta<\frac{1}{2}$, it is shown that $N^{1-2 \eta}(\hat{c}-c) \rightarrow_{d} w \Upsilon$, where $w$ is a scaling factor and the distribution function for $\Upsilon$ is known. As $\lambda_{n}$ tends to zero, the rate of convergence is reduced but a simpler asymptotic distribution for $\hat{c}$ can be derived, see also Caner and Hansen (2004). In particular, Hansen (1999) shows that an analytic inverse form of the asymptotic distribution of the $L R$ statistic can be given by $-2 \log (1-\sqrt{1-\alpha})$. In this case, the critical values are $6.53,7.35$ and 10.5 for $\alpha=10 \%, 5 \%$ and $1 \%$, respectively. Next, the confidence interval for $\hat{c}$, denoted $C_{\alpha}=\left[c_{L}, c_{H}\right]$, will be selected from the grid set, $\mathcal{C}$, such that the $L R$ statistics evaluated at $C_{\alpha}$ are smaller than the critical value (crit) at the $\alpha$-significance level.

Under the maintained assumption that the transition variable, $q_{i t}$, is stationary and exogenous, the GMM estimators of $\boldsymbol{\theta}(c)$ are asymptotically independent of the threshold estimate such that inference on $\boldsymbol{\theta}$ can proceed as if $\hat{c}$ were the true value, e.g., Hansen (1999, 200) and Caner and Hansen (2004). Hence, it is easily seen that the asymptotic distribution of $\hat{\boldsymbol{\theta}}_{G M M_{2}}(\hat{c})$ is normal with the covariance matrix estimated by:

$$
\widehat{\operatorname{Var}}\left(\hat{\boldsymbol{\theta}}_{G M M_{2}}(\hat{c})\right)=\left[\mathbf{Z}(\hat{c})^{\prime} \mathbf{W}(\hat{c}) \hat{\mathbf{V}}_{G M M_{2}}(\hat{c})^{-1} \mathbf{W}(\hat{c})^{\prime} \mathbf{Z}(\hat{c})\right]^{-1} .
$$

\subsection{Testing for Threshold Effects}

\subsubsection{Bootstrap-based Testing Procedure}

In this subsection, we propose a bootstrap-based procedure to test the null hypothesis of no threshold effect (one regime) in (4) against the alternative hypothesis of a threshold effect (two regimes) by extending the Hansen (1999) procedure. The null hypothesis of 
no threshold effect $\left(\boldsymbol{\theta}_{1}=\boldsymbol{\theta}_{2}\right)$ is given by:

$$
H_{0}: \mathbf{R} \boldsymbol{\theta}=\mathbf{0},
$$

where $\mathbf{R}=\left[\mathbf{I}_{K+1},-\mathbf{I}_{K+1}\right]$. We then construct the Wald statistic by:

$$
\mathcal{W}(\hat{c})=\{\mathbf{R} \hat{\boldsymbol{\theta}}(\hat{c})\}^{\prime}\left\{\mathbf{R} \widehat{\operatorname{Var}}(\hat{\boldsymbol{\theta}}(\hat{c})) \mathbf{R}^{\prime}\right\}^{-1}\{\mathbf{R} \hat{\boldsymbol{\theta}}(\hat{c})\}
$$

where $\hat{\boldsymbol{\theta}}$ is the GMM estimator. Since the threshold parameter is not identified under the null of no threshold effect, (18), the testing procedure is nonstandard (e.g., Davies, 1987; Andrews and Ploberger, 1994, 1996; Hansen, 1996). Thus, a natural test statistic for $H_{0}$ is given by:

$$
\sup W=\sup _{c \in C} \mathcal{W}(c) .
$$

Given that the model is linear in $\boldsymbol{\theta}$ for each $c$, the Wald statistic is computed in a straightforward manner using the asymptotic variance estimate formula (17). However, the limiting distribution of $\sup W$ is not asymptotically pivotal and its critical values cannot be tabulated.

Hansen $(1996,1999)$ suggests to use bootstrap techniques to obtain a valid asymptotic $p$-value of the Wald statistic. Following this approach, we first estimate (6) under the alternative hypothesis, and save the residuals, $\Delta \hat{e}_{i t}(\hat{c})$, and the Wald statistic, $\mathcal{W}(\hat{c})$. We collect the residuals in $\Delta \hat{\mathbf{e}}_{i}=\left(\Delta \hat{e}_{i 3}(\hat{c}), \ldots, \Delta \hat{e}_{i T}(\hat{c})\right)^{\prime}$, and $\Delta \hat{\mathbf{e}}=\left(\Delta \hat{\mathbf{e}}_{1}, \ldots, \Delta \hat{\mathbf{e}}_{N}\right)$. We next consider the DGP under the null, estimate the null model, (3) by the two-step GMM and save the parameter estimates by $(\tilde{\phi}, \tilde{\boldsymbol{\pi}})$. Assuming that the initial values, $\ell_{i 1}$ and $\ell_{i 2}$, and $\mathbf{x}_{i t}$ are given, we generate the $b$ th bootstrap samples of $\ell_{i t}$ under $H_{0}$ as follows:

$$
\ell_{i t}^{(b)}=\left\{\begin{array}{ll}
\ell_{i t} & t=1,2 \\
\ell_{i, t-1}^{(b)}+\Delta \ell_{i t}^{(b)} & t \geq 3
\end{array}, b=1, \ldots, B\right.
$$

where

$$
\Delta \ell_{i t}^{(b)}=\tilde{\phi} \Delta \ell_{i, t-1}^{(b)}+\tilde{\boldsymbol{\pi}}^{\prime} \Delta \mathbf{x}_{i t}+\Delta e_{i t}^{(b)}
$$

and $\Delta e_{i t}^{(b)}$ are the $b$ th bootstrap samples of $\Delta e_{i t}$ obtained by re-sampling from $\Delta \hat{\mathbf{e}}$ with replacement. Next, using the bootstrap samples, $\ell_{i t}^{(b)}$, we re-estimate the model under the alternative hypothesis, (6), and evaluate the Wald statistic by:

$$
\mathcal{W}(\hat{c})^{(b)}=\left\{\mathbf{R} \hat{\boldsymbol{\theta}}^{(b)}(\hat{c})\right\}^{\prime}\left\{\mathbf{R} \widehat{\operatorname{Var}}\left(\hat{\boldsymbol{\theta}}^{(b)}(\hat{c})\right) \mathbf{R}^{\prime}\right\}\left\{\mathbf{R} \hat{\boldsymbol{\theta}}^{(b)}(\hat{c})\right\}, b=1, \ldots, B
$$


Repeating this procedure $B$ times, the bootstrap-based $p$-value of the statistic is evaluated by: ${ }^{14}$

$$
p \text {-value }=\frac{1}{B} \sum_{b=1}^{B} 1\left\{\mathcal{W}(\hat{c})^{(b)}>\mathcal{W}(\hat{c})\right\} .
$$

The null hypothesis in (18) is rejected if this $p$-value is smaller than the significance level.

Finally, under the assumption that $q_{i t}$ is exogenous such that the GMM estimators of $\boldsymbol{\theta}(c)$ are asymptotically independent of $\hat{c}$, we note that the bootstrap-based inference for the threshold effect described above should attain the first-order asymptotic distribution, and thus the $p$-values are asymptotically valid (e.g., Andrews and Ploberger, 1994; Hansen, 1996, 1999).

\subsubsection{Monte Carlo Simulation Studies}

Here, we conduct Monte Carlo simulation studies in order to investigate the finite-sample performance of the bootstrap-based inference as described above. The data generating process for leverage, $\ell_{i t}$, is based on the threshold partial adjustment model:

$$
\Delta \ell_{i t}=\delta_{1}\left(\ell_{i t}^{*}-\ell_{i, t-1}\right) 1_{\left\{q_{i t} \leq c\right\}}+\delta_{2}\left(\ell_{i t}^{*}-\ell_{i, t-1}\right) 1_{\left\{q_{i t}>c\right\}}+\alpha_{i}+e_{i t},
$$

where target leverage is constructed as a non-linear function of a scalar covariate, $x_{i t}$ :

$$
\ell_{i t}^{*}=\beta_{1} x_{i t} 1_{\left\{q_{i t} \leq c\right\}}+\beta_{2} x_{i t} 1_{\left\{q_{i t}>c\right\}}, i=1, \ldots, N ; t=1, \ldots, T,
$$

Combining (23) and (24), we obtain:

$$
\ell_{i t}=\left(\phi_{1} \ell_{i, t-1}+\pi_{1} x_{i t}\right) 1_{\left\{q_{i t} \leq c\right\}}+\left(\phi_{2} \ell_{i, t-1}+\pi_{2} x_{i t}\right) 1_{\left\{q_{i t}>c\right\}}+\alpha_{i}+e_{i t},
$$

where $\phi_{j}=1-\delta_{j}$ and $\pi_{j}=\delta_{j} \beta_{j}$ for $j=1,2$. Next, we construct the covariate, $x_{i t}$ as a stationary $\mathrm{AR}(1)$ process:

$$
x_{i t}=\rho x_{i, t-1}+u_{i t},
$$

where $|\rho|<1$ and a transition variable by:

$$
q_{i t}=\mu_{q}+v_{i t}
$$

We further impose the following restrictions. $x_{i t}$ and $q_{i t}$ are exogenously generated such that $\mathbf{E}\left[u_{i t} e_{i t}\right]=0, \mathbf{E}\left[u_{i t} v_{i t}\right]=0$ and $\mathbf{E}\left[v_{i t} e_{i t}\right]=0 . u_{i t}$ and $v_{i t}$ follow i.i.d. normal distributions, such that $u_{i t} \sim i i d N\left(0, \sigma_{u}^{2}\right)$ and $v_{i t} \sim i i d N\left(0, \sigma_{v}^{2}\right)$. To allow for heteroscedasticity over time and across cross-section, we assume that $e_{i t}$ follows an $\mathrm{ARCH}(1)$ process (Ev-

\footnotetext{
${ }^{14} \mathrm{An}$ alternative approach is to construct the $\sup W$ statistic, say $\sup W^{(b)}$, from the bootstrapped sample and evaluate the bootstrap $p$-value by the frequencies of $\sup W^{(b)}$ that exceed the sample statistic, $\sup W$.
} 
eraert and Pozzi, 2007):

$$
e_{i t}=h_{i t}^{1 / 2} \xi_{i t}, h_{i t}=\omega+a e_{i, t-1}^{2}, \xi_{i t} \sim i i d N(0,1)
$$

The initial value of $e_{i t}$ can be obtained from the stationary distribution of $e_{i t}$ such that $e_{i 1}=\left(\frac{\omega}{1-a}\right)^{1 / 2} \xi_{i 1}$ and $\xi_{i 1} \sim i i d N(0,1)$. A special case of homoscedastic errors is obtained by imposing $a=0$ such that $e_{i t}=\omega^{1 / 2} \xi_{i t}$. Unobserved individual effects, $\alpha_{i}$ are assumed to be uniformly distributed, i.e., $\alpha_{i} \sim U(-\alpha, \alpha)$. Assume that $\operatorname{Var}\left(\alpha_{i}\right)$ is proportional to $\sigma_{e}^{2}$ such that $\operatorname{Var}\left(\alpha_{i}\right)=\alpha^{2} / 3=\kappa \sigma_{e}^{2}$, and so $\alpha=\sqrt{3 \kappa} \sigma_{e}>0 .{ }^{15}$

Throughout the simulations, we fix $\ell_{i 0}=0$ and generate $T+10$ time period observations and then discard the first 10 observations to reduce the potential effects of starting values. We consider $N=\{100,200\}$ and set the parameters $\left(\delta_{1}, \beta_{1}, \rho, \mu_{p}, \sigma_{u}, \sigma_{v}, \kappa\right)=$ $(0.5,1,0.5,0,1,1,3)$. We set the number of replications at 1,000 , and the number of bootstrap iterations at 100 per each estimation of (25). We estimate the threshold model (25) by the two-step GMM estimator described in Section 4.1.

\section{[Insert Table 1 about here]}

Table 1 reports the simulation results for the empirical frequencies of the bootstrapbased Wald statistic rejecting the null hypothesis of no threshold effect at the $1 \%$ and the $5 \%$ significance levels. The empirical sizes of the tests, reported in the row with $\left(\delta_{2}, \beta_{2}\right)=(0.5,1.0)$, are reasonably close to the nominal levels for all cases considered, irrespective of the presence of heteroscedasticity. Importantly, we find that the power of the tests increases monotonically with the absolute difference between the parameter values. For example, when $\left|\delta_{1}-\delta_{2}\right| \geq 0.2$ and $\left|\beta_{1}-\beta_{2}\right| \geq 0.2$, the power reaches unity as $N=200$. Interestingly, we find that the power of the tests becomes slightly asymmetric near the null hypothesis, showing that the test becomes slightly more powerful when $\delta_{2}<0.5$ (relatively slow adjustment) than when $\delta_{2}>0.5$ (relatively fast adjustment), though such difference will become negligible when $\left|\delta_{1}-\delta_{2}\right|>0.1{ }^{16}$ In sum, the above Monte Carlo simulation results clearly demonstrate that the empirical size and power performance of the bootstrap-based inference is highly reliable in finite samples, the size of which is typically encountered in empirical capital structure studies.

\footnotetext{
${ }^{15} \kappa=1$ implies that the individual effects are uniformly distributed over $(-\sqrt{3}, \sqrt{3})$. We have also considered cases with larger or smaller ranges and obtained qualitatively similar simulation results.

${ }^{16}$ In the empirical section below, we find that the asymmetric speeds of adjustment range between 0.5 and 0.8 , and that the difference between them is mostly greater than 0.1, e.g., ranging between 0.113 and 0.325 .
} 


\section{$5 \quad$ Data and Empirical Results}

\subsection{Data and Sample Selection}

We investigate a panel of UK firms collected from the Datastream database. Using Datastream's research sample (comprising 1,683 firms), we collected company accounting data from the earliest possible year to January 2004 and constructed an unbalanced panel of nearly 20,000 firm-year observations. Following previous studies (e.g., Ozkan, 2001; Antoniou et al., 2008; Dang, 2011), we applied a number of standard data restrictions. First, firms operating in financial sectors (banks, insurance and life assurance companies and investment trusts) and in utility sectors (electricity, water and gas) were excluded since they are subject to different accounting considerations. Second, in order to use the GMM estimators that require lagged instruments, only firms with at least five years of observations were retained (Arellano and Bond, 1991). Finally, observations that have missing data were removed. ${ }^{17}$ Our final sample consists of 859 companies and 5,393 firmyear observations, with the longest time series of 8 years over the period 1996-2003. The definitions and summary statistics for the variables under consideration are provided in Tables 2 and 3, respectively.

[Insert Tables 2 and 3 about here]

\subsection{Regression Results for the Partial Adjustment Model}

Table 4 reports the regression results for the symmetric, non-threshold partial adjustment model of leverage given by (3). Panel A reports the short-run dynamics, including the short-run coefficients, the speed of adjustment, and standard diagnostic tests (i.e., the AR(2) and Sargan tests) while Panel B contains the long-run coefficients on the determinants of target leverage. ${ }^{18}$

We employ two consistent estimators, AH-IV and GMM and report their regression results in the respective columns in the table. ${ }^{19}$ Overall, the AH-IV and GMM regression results are reasonable as the $\mathrm{AR}(2)$ and Sargan tests of no second-order serial correlation and valid instruments cannot be rejected at conventional significance levels, and the estimated (long-run) coefficients are statistically significant with the expected signs. ${ }^{20}$

\footnotetext{
${ }^{17}$ As in previous UK studies (e.g., Dang, 2011), a large number of observations were dropped due to the unavailability of data in firms' cash flow statements.

${ }^{18}$ Throughout the empirical analysis, we follow the literature (e.g., Ozkan, 2001) and include (strictly exogenous) time effects to control for macroeconomic and global effects, e.g., changes in the state of the economy, interest rates and prices, accounting standards and other regulations.

${ }^{19} \mathrm{We}$ have also experimented with the (least-squares) POLS and FE estimators, which in theory provide biased estimates of the speed of adjustment and consequently the long-run coefficients. Indeed, (unreported) results show that the POLS estimate of the speed of adjustment seems to be downward biased while the FE estimate appears to contain an upward bias.

${ }^{20}$ Recently, Antoniou et al. (2008) and Lemmon et al. (2008) have suggested employing the Blundell
} 
The speed of adjustment is estimated at $53 \%$ and $59 \%$, respectively by AH-IV and GMM. These results suggest that UK firms can close more than a half of their deviation from target leverage within a year. Using the concept of half-life, this suggests that UK firms only need between 0.91 and 0.76 years to halve their deviation from target leverage. These speeds are consistent with the previously reported UK results (Ozkan, 2001; Dang, 2011) but faster than the speeds estimated for US firms (Flannery and Rangan, 2006; Lemmon et al., 2008; Huang and Ritter, 2009).

\section{[Insert Table 4 about here]}

Next, we turn to the AH-IV and GMM results regarding the long-run coefficients reported in Panel B. Growth opportunities have a significantly negative effect on leverage, which is consistent with the prediction that high-growth firms lower leverage in order to mitigate the under-investment problem (Myers, 1977). The impact of profitability on target leverage is significantly negative, which is consistent with the prior empirical evidence (Titman and Wessels, 1988; Rajan and Zingales, 1995), and supportive of both the pecking order theory (Myers and Majluf, 1984; Myers, 1984) and the dynamic tradeoff theory (e.g., Strebulaev, 2007). The coefficient on tangibility is significantly positive, which is in line with the trade-off view that tangibility can be used as a security to avoid the asset substitution problem and reduce the agency costs of debt (e.g., Frank and Goyal, 2007). The coefficient on non-debt tax shields is significantly negative, supporting the hypothesis that non-debt tax shields are a substitute for the tax benefits of debt so firms with high non-debt tax shields should have less debt (DeAngelo and Masulis, 1980). Firm size has a significantly positive coefficient, which is in line with the prediction that large firms face low bankruptcy, agency and transaction costs and thus have easier access to debt financing (Frank and Goyal, 2007). In sum, the results for the long-run coefficients are empirically plausible and consistent with the trade-off framework.

The results discussed so far assume that firms undertake capital structure adjustments at the same rate toward a homogeneous target leverage ratio. We now turn to discuss the main empirical results obtained from the proposed dynamic panel threshold model of leverage, (4).

and Bond (1998) SYSGMM to address the weak instruments problem of the GMM estimator. This method is mostly useful when the dependent variable, leverage in this context, is close to a random walk process (Blundell and Bond, 1998). As documented by Frank and Goyal (2007), however, corporate capital structure in the US has been remarkably stable over the last half century. Our unreported analysis shows that the aggregate UK leverage ratio has also been stable over our sample period. Unless there is a way of choosing an optimal set of instruments for alternative GMM estimators, the SYSGMM that employs more instruments than the GMM is likely to suffer from more severe over-fitting bias problems, especially in small samples (Zilak, 1997). We have adopted SYSGMM in empirical analysis but found that the Sargan test strongly rejects the validity of the instruments used. For all these reasons, we do not consider the SYSGMM estimator in the paper. 


\subsection{Regression Results for the Threshold Partial Adjustment Model}

Table 5 presents the results from the two-step GMM estimation of the threshold partial adjustment model, (4), for three transition variables financing imbalance, growth opportunities and firm investment. Firms are classified into the low (high) regime when the value of the transition variable is less than or equal to (greater than) the estimated threshold value. Panel A reports the short-run dynamics, namely the coefficients on lagged leverage and the determinants of leverage, as well as the Wald test statistics for the null hypothesis of (individual) short-run symmetry. ${ }^{21}$ It also reports the implied speeds of adjustment, the threshold value and its confidence interval, as well as the (bootstrap-based) Wald test for the threshold effect (one versus two regimes). Further, this panel contains the conventional $\mathrm{AR}(2)$ and Sargan test statistics, which allow us to check the validity of the instruments used in the GMM regressions. It is worth noting that throughout the empirical analysis below, both tests are not rejected at the $5 \%$ significance level, suggesting that all GMM regressions use valid instruments. ${ }^{22}$ Panel B of the table reports the long-run coefficients and the Wald test statistics under the null of long-run symmetry. Note that these tests enable us to shed light on the interesting question of whether firms in different regimes adjust toward heterogeneous target leverage. Finally, in Panel C, we report several important characteristics of firms being classified into the low and high regimes. In particular, we examine the mechanisms (i.e., equity versus debt financing) in which firms adjust their capital structure toward target leverage.

[Insert Table 5 about here]

\section{Financing imbalance}

The bootstrap-based regime test statistic in Panel A, column (1) first indicates that the null of one regime can be convincingly rejected such that there exists a threshold effect conditional on firms' financing imbalance. This finding is consistent with the evidence of short-run asymmetries in several coefficients (i.e., tangibility, non-debt tax shields, growth and firm size) and more importantly, in the speed of adjustment. Indeed, firms with higher financing imbalance have a faster speed of adjustment than those with lower imbalance: the former firms adjust at a rate of $75 \%$, compared to the rate of $50 \%$ for the latter firms. The difference in the two adjustment speeds of nearly $25 \%$ is both statistically and economically significant. Moreover, the threshold value is estimated at

\footnotetext{
${ }^{21}$ Under two regimes, this Wald statistic follows the asymptotic $\chi_{1}^{2}$ distribution.

${ }^{22}$ As in a previous footnote, although our econometric framework allows for a straightforward extension using the Blundell and Bond (1998) SYSGMM, we do not consider this estimator here because in unreported tests, the validity of the SYSGMM instruments is always rejected at the $1 \%$ level. The over-fitting bias problem appears to be even more serious in dynamic panel threshold models.
} 
0.07, at the 78th percentile of the distribution of the (regime-switching) variable financing imbalance. This finding suggests that consistent with our prediction, the sign of the imbalance does matter. Specifically, firms with a large financing deficit have a quicker speed of adjustment than those with a small deficit or a financing surplus. It is consistent with the argument that firms having more pressure and/or more incentive to cover their financing deficit undertake quicker adjustment, and is in line with recent international evidence on the asymmetric impact of firms' financing deficit and surplus on their speed of capital structure adjustment (Dang et al., 2011).

The results in Panel B show that the long-run coefficients are generally significant with the expected signs (except for non-debt tax shields and profitability in the high regime). Further, these coefficients appear to differ in magnitude between the two groups of firms. Specifically, the effects of asset tangibility and non-debt tax shields are significantly stronger for firms with low financing imbalance than for those with high imbalance. The effects of profitability and growth opportunities are also different, albeit only at $10 \%$. Taken together with the results in Panel A, these findings suggest that not only firms with different levels of financing imbalance adjust their capital structure at different rates but they also adjust toward different long-run target leverage ratios. In short, conditional on firms' financing imbalance, there is evidence of both short-run and long-run asymmetries in capital structure adjustment.

The results in Panel $\mathrm{C}$ confirm that firms adjusting relatively quickly have a large and positive financing deficit (0.21) while those adjusting relatively slowly have a surplus (0.03), which is consistent with the results regarding the threshold value reported in Panel A. Further, the former firms have a positive deviation from target leverage, indicating they are on average over-levered. ${ }^{23}$ This observation is consistent with the recent US evidence that over-levered firms tend to make fast adjustment to avoid the large financial distress/bankruptcy costs associated with having above-target leverage (Byoun, 2008). The statistics on firms' external financing decisions show that these firms issue both debt and equity to cover their financing deficit, although they rely considerably more on net equity issues than net debt issues (0.20 versus 0.07$)$. Note that this financing pattern is consistent with target adjustment behavior because through equity issues, over-levered firms can reduce their leverage from the above-target level.

\section{Growth opportunities}

In column (2), the joint (regime) test of homogeneous short-run coefficients is rejected at $1 \%$, thus strongly suggesting the presence of a threshold effect conditional on firms' growth opportunities. Further, the results show that low-growth and high-growth firms

\footnotetext{
${ }^{23}$ The variable deviation is equal to the actual leverage ratio $\left(\ell_{i t}\right)$ less the estimated target leverage ratio $\left(\hat{\ell}_{i t}^{*}=\hat{\boldsymbol{\beta}}^{\prime} \mathbf{x}_{i t}\right.$ with $\hat{\boldsymbol{\beta}}$ being the long-run coefficients estimated from (4)).
} 
adjust toward their target leverage at the rates of $54 \%$ and $70 \%$, respectively. This finding appears to support our earlier prediction that high-growth firms undertake faster leverage adjustment thanks to their frequent visits to the capital markets, which in turn provide them with more opportunities to find an appropriate mix of debt and equity. Surprisingly, however, these two speeds of adjustment are not statistically different from each other according to the test statistic. This mixed finding may reflect the theoretically ambiguous relation between growth opportunities and capital structure adjustments discussed earlier.

In Panel B, there is some evidence that low-growth and high-growth firms have heterogeneous target leverage as the long-run coefficients seem to be relatively larger in magnitude for the former firms. In particular, the effects of growth opportunities and firm size are both economically and statistically stronger for low-growth firms than for their high-growth counterparts. The results regarding the differential effects of growth opportunities indicate that firms are more concerned about free cash flow problems, which are most relevant for low-growth, cash rich firms (Jensen, 1986), than about underinvestment incentives, which are likely to arise in the presence of high growth opportunities (Myers, 1977). On the other hand, the weaker impact of firm size on target leverage for high-growth firms may be explained by the tendency of these firms to eschew debt in order to avoid the debt overhang problem. Overall, we find some statistical evidence for long-run asymmetries and heterogeneity in target leverage but not for short-run asymmetry in the speed of adjustment. Put it differently, firms with low- and high-growth opportunities may adjust toward heterogeneous leverage targets, albeit at homogeneous rates.

The results in Panel $\mathrm{C}$ reveal that low-growth and high-growth firms have different characteristics. Most notably, high-growth firms are over-levered with a financing deficit, which they offset by making relatively large (net) equity issues. These characteristics are similar to those of firms with high financing imbalance, i.e. those that have a fast speed of adjustment in column (1).

\section{Firm investment}

It can be seen from Panel A, column (3) that the bootstrap-based regime test cannot be rejected, suggesting that there is no threshold effect conditional on firm investment. This finding is possibly driven by the lack of short-run asymmetries in the coefficients on the determinants of leverage. Indeed, individual test results confirm that all coefficients are not statistically different between the two groups of firms, at the $5 \%$ level. However, the speed of adjustment seems to be faster for firms with large investment $(77 \%)$ than for those with small investment (59\%). Importantly, the difference in the speeds $(18 \%)$ is not only economically significant but also statistically significant. This finding is thus inconsistent with the prediction that firms facing potential financial constraints due to 
large spending on investment projects should have a slow speed of adjustment. On the other hand, it seems to support the argument that large capital expenditures that require external funds may provide firms with opportunities to choose an appropriate mix of new debt and equity in order to quickly move toward their optimal capital structure.

The results in Panel B suggest that firms with small investment and those with large investment may consider heterogeneous leverage targets. The long-run coefficients are generally larger in magnitude for firms in the low regime than for those in the high regime. In particular, the effects of profitability and firm size on target leverage are statistically different for these two groups of firms. The stronger inverse relation between profitability and target leverage for firms in the low regime can be explained by the fact that firms with limited capital expenditures may not need to use (external) debt, especially when they are profitable and have retained earnings.

Our further analysis of the firm-specific characteristics in Panel C suggests that firms classified as having more investment, i.e., those belonging to the high regime and have a faster speed of adjustment, tend to have a significantly higher financing deficit, which they then offset by issuing both debt and equity. This pattern is clearly consistent with the argument above that firms with large capital expenditures have more opportunities to adjust leverage thanks to their visits to the capital markets. Moreover, the results also show that these firms' leverage adjustment is mainly driven by (net) equity issues, rather than by debt issues, which is in line with target adjustment behavior given that they have above-target leverage (as indicated by a positive deviation) and thus little incentive to issue additional debt.

[Insert Table 6 about here]

We next turn to Table 6, which reports the regression and test results for the threshold partial adjustment model (4) using the remaining transition variables, namely profitability, firm size and volatility. The format of this table is similar to that of Table 5 described above.

\section{Profitability}

In Panel A, column (1), the bootstrap-based regime test suggests a threshold effect as the null of one regime is rejected at 5\%. On closer inspection, however, we find almost no evidence of short-run asymmetries as the individual (short-run) coefficients are not statistically different between firms in the two regimes (except for growth opportunities). Next, the implied speeds of adjustment for firms with low and high profitability are $64 \%$ and $74 \%$, respectively, which appears to support the argument that firms with low profitability are highly levered and so have more incentive to revert to target leverage in order to avoid financial distress. Nevertheless, these speeds are faster than the estimated 
speed in the linear model reported in Table 4 while the difference in these speeds (of 10\%) is not statistically significant.

In Panel B, there is evidence of long-run asymmetries in the impact of tangibility and growth opportunities on target leverage, although surprisingly there is no such evidence for profitability. Overall, firms with low and high profitability may adjust toward heterogeneous target leverage (i.e., long-run asymmetries), although there is no statistical evidence in favor of short-run symmetries. Finally, in Panel C, the characteristics of the two groups of firms with different levels of profitability are significantly different (except for net debt issued). Compared to the results from Table 5, firms that appear to adjust at a quick rater, i.e., highly profitable firms, are also over-levered but have a surplus and rely on both debt and equity financing activities to cover their imbalance.

\section{Firm size}

The results in column (2) show that the speeds of adjustment for small and large firms are respectively $77 \%$ and $62 \%$, which are faster than the speed estimated for the symmetric model discussed in Subsection 5.2. The magnitude of these speeds appears to be consistent with the argument that due to facing lower cash flow volatility and financial distress costs as well as fewer debt covenants, large firms have less incentive and external pressure to adjust capital structures, implying a slower speed of adjustment. However, the test statistic shows that the difference in the two speeds of adjustment (of 15\%) is not statistically significant. Moreover, according to the regime test, there is no evidence of a threshold effect conditional on firm size, which is further corroborated by the lack of asymmetries in the short-run coefficients on the determinants of leverage. This finding is inconsistent with recent evidence on the relation between firm size and the speed of adjustment (Dang et al., 2011; Faulkender et al., 2011). Note however that in Panel B, there is almost no evidence of long-run asymmetries, except for tangibility, which has a statistically different impact on target leverage for small and large firms. The effects of profitability and growth are only marginally different at $10 \%$. Taken together, the results regarding firm size do not provide evidence for short-run and long-run asymmetries in any meaningful sense.

\section{Volatility}

The results in column (3) provide strong evidence of joint short-run asymmetries, as the bootstrap-based regime test is rejected at 5\%. More importantly, this finding is driven by the heterogeneity in the speed of adjustment alone because there is no evidence of significant asymmetries in the remaining short-run coefficients. Indeed, firms with low and high earnings volatility adjust at different rates (67\% versus $56 \%$ ) and although the difference in these speeds is only $11 \%$, it is statistically significant at $1 \%$. This finding is 
consistent with the prediction that firms with low earnings volatility face a lower cost of capital and so have more scope to undertake capital structure adjustment.

In Panel $\mathrm{B}$, there is some weak evidence of long-run asymmetries as only firm size has a differential impact on target leverage for the two groups of firms. Firm size may matter more for firms with volatile earnings possibly because these firms may face high (fixed) costs of capital and have limited access to debt financing. Finally, in Panel C, the results show that firms that adjust more quickly (i.e., those with low volatility) are over-levered and have a financing deficit. Although these firms retire debt, they mainly rely on (net) equity issues to reduce their above-target leverage, consistent with target adjustment behavior. These characteristics are generally similar to those documented for firms that adjust with a relatively quick speed in Table 5 .

\section{Discussion and Summary of Results}

The results above combine to provide a complex, yet interesting picture of firms' asymmetric capital structure adjustments in both the short and long run. Overall, we are able to identify two distinct sets of results. The first set consists of cases where the transition variable used is either financing imbalance, investment or volatility. The common finding in these cases is that there are significant asymmetries in both the speed of adjustment and the long-run target leverage relationships. ${ }^{24}$ Indeed, firms having large financing imbalance (or a deficit), large investment or low earnings volatility adjust at statistically quicker rates than those with the opposite characteristics. In terms of the long-run coefficients, their signs are empirically plausible, the same as in the symmetric partial adjustment model discussed in Subsection 5.2. More importantly, the effects of tangibility, profitability and firm size on target leverage tend to be relatively stronger for firms that adjust with a relatively slower speed. This finding may shed light on a possible relation between the short-run and long-run adjustment mechanisms, i.e., the speed of adjustment seems to be inversely proportional to the size of the adjustment in (longrun) target leverage as proxied by the effects of the determinants of such target. Next, we also document a consistent pattern about firms having faster speeds of adjustment: these firms are significantly over-levered with a financing deficit and a considerably large (positive) deviation from their target leverage. ${ }^{25}$ Moreover, these firms revert to target leverage mainly via equity issues, which is consistent with target adjustment behavior.

The second set of results consists of two cases with the transition variable being either

\footnotetext{
${ }^{24}$ Growth opportunities may also be added to this group, though there is no statistical evidence of heterogeneity in the speed of adjustment for this case. Also recall that for firm investment, the regime test does not suggest a threshold effect, possibly due to a lack of short-run asymmetries in the coefficients on the determinants of leverage. Hence, the results for this transition variable should also be treated with care.

${ }^{25}$ Using the (absolute) deviation from target leverage as a transition variable could be useful for verifying this finding, although such an approach is not permitted in our current modeling that assumes exogenous transition variables. We leave this issue for future research.
} 
profitability or firm size. In both cases, we find no statistical evidence of asymmetry in the speed of adjustment. Moreover, compared to the regression results for the linear model in Subsection 5.2, the estimated speeds of adjustment are both faster than the (symmetric) speed of adjustment in the linear model. Empirically, one should expect the parameters in the symmetric model to be close to the weighted means of those in the low and high regimes; yet we find contrasting evidence here. Hence, the results regarding the estimated adjustment speeds should be treated with great caution. Note that this finding is inconsistent with recent research (Dang et al., 2011; Faulkender et al., 2011) that documents significant asymmetry in the speed of adjustment conditional on profitability and firm size. One possible explanation for our different finding is that unlike previous studies, we adopt the one-stage estimation procedure allowing for asymmetries in long-run target leverage relationships. For example, we document some evidence of heterogeneity in target leverage in that there are significantly different effects of tangibility and size on long-run target leverage for firms with relatively slow speeds of adjustment (at least in terms of magnitude).

To sum up, the above discussions indicate that using the first group of variables, namely financing imbalance, investment and volatility, as the regime-switching variable provides reasonable empirical evidence of (short-run and long-run) asymmetries in capital structure adjustments. In contrast, profitability and firm size do not seem to be good candidates for the regime-switching transition variable.

\section{Conclusions}

The (dynamic) trade-off theory of capital structure implies that firms facing differential adjustment costs may follow different paths toward their target leverage. This paper proposes a new empirical approach to test this prediction by modeling short-run and longrun asymmetries in capital structure adjustments. Specifically, our testing framework entertains a possibility that firms may adjust at different rates toward heterogeneous leverage targets. In terms of methods, we have advanced a dynamic panel threshold model of leverage and developed appropriate econometric techniques to consistently estimate the speeds of adjustment in different regimes associated with differential adjustment costs. We have also provided a valid bootstrap-based procedure to test for the threshold effect.

We have documented some evidence of asymmetries in firms' adjustment toward target leverage. Firms with large financing imbalance (or a deficit), large capital expenditures or low earnings volatility have a significantly faster speed of adjustment than those with the opposite characteristics. Further, we provide some evidence of long-run asymmetries that not only do firms with such characteristics adjust at different rates, but they also seem to adjust toward heterogeneous leverage targets. Firms that have a significantly faster speed of adjustment possess important characteristics: they are significantly over- 
levered with a financing deficit. These firms then revert to their target leverage and offset their deficit mainly via equity issues rather than by debt issues/retirements. This finding suggests that firms tend to make quicker adjustment to avoid the potentially large financial distress costs caused by having above-target leverage, which is consistent with the dynamic trade-off theory.

On the other hand, conditional on profitability and firm size, two commonly used proxies for adjustment costs, we find no evidence of short-run asymmetry in the speed of adjustment and only limited evidence in favor of long-run asymmetries. Noticeably, in both cases, the estimated speeds of adjustment in the low and high regimes are always faster than the speed of adjustment estimated for the linear model. This, therefore, suggests that using profitability and firm size as the transition variable in our regimeswitching framework may not produce sensible empirical results.

A few words of caution are in order. While the empirical framework developed in our paper is capable of examining the validity of the dynamic trade-off theory, it does not directly test the predictions of alternative views of capital structure such as the pecking order theory, the market timing and inertia hypotheses. Our approach to estimating target leverage follows the convention in the capital structure literature so it may be subject to potential empirical problems, such as the presence of a mass point at zeroleverage, non-linearity of leverage ratios and survivorship biases in firm-level panel data (e.g., Welch, 2007; Cook et al., 2008). Further, the empirical evidence in favor of target adjustment behavior and dynamic rebalancing of leverage may be affected by mechanical mean reversion (Shyam-Sunder and Myers, 1999; Chen and Zhao, 2007; Chang and Dasgupta, 2009), and be consistent with both the trade-off and modified pecking order theories (Leary and Roberts, 2005). In terms of methods, our modeling approach only allows for exogenous regime-switching in dynamic panel threshold models so it would be desirable for future research to consider endogenous regime-switching mechanisms (Kourtellos et al., 2009). 


\section{References}

Ahn, S., C. Schmidt, P., 1995. Efficient Estimation of Models for Dynamic Panel Data. Journal of Econometrics 68, 5-27.

Ahn, S., C. Schmidt, P., 1997. Efficient Estimation of Dynamic Panel Data Models: Alternative Assumptions and Simplified Estimation. Journal of Econometrics 76, 309321.

Alvarez, J., Arellano, M., 2003. The Time Series and Cross-Section Asymptotics of Dynamic Panel Data Estimators. Econometrica 71, 1121-1159.

Anderson, T.W., Hsiao, C., 1982. Formulation and Estimation of Dynamic Models Using Panel Data. Journal of Econometrics 18, 47-82.

Andrews, D.W.K., Ploberger, W., 1994. Optimal Tests When A Nuisance Parameter Is Present Only under The Alternative. Econometrica 62, 1383-1414.

Andrews, D.W.K., Ploberger, W., 1996. Testing for Serial Correlation Against an $\operatorname{ARMA}(1,1$,$) Process. Journal of the American Statistical Association 91, 1331-1342.$

Antoniou, A., Guney, Y., Paudyal, K., 2008. The Determinants of Capital Structure: Capital Market Oriented versus Bank Oriented Institutions. Journal of Financial and Quantitative Analysis 43, 59-92.

Arellano, M., 2003. Panel Data Econometrics: Advanced Texts in Econometrics. Oxford University Press, Oxford.

Arellano, M., Bond, S.R., 1991. Some Tests of Specification for Panel Data: Monte Carlo Evidence and an Application to Employment Equations. Review of Economic Studies 58, 227-297.

Arellano, M., Bover, O., 1995. Another Look at the Instrumental Variable Estimation of Error Components Models. Journal of Econometrics 68, 29-51.

Baker, M., Wurgler, J., 2002. Market Timing and Capital Structure. Journal of Finance $57,1-32$.

Blundell, R.W., Bond, S.R., 1998. Initial Conditions and Moment Restrictions in Dynamic Panel Data Models. Journal of Econometrics 87, 115-143.

Bradley, M., Jarrell, G.A., Kim, E.H., 1984. On the Existence of an Optimal Capital Structure: Theory and Evidence. Journal of Finance 39, 857-878.

Brennan, M.J., Schwartz, E.S., 1978. Corporate Income Taxes, Valuation and the Problem of Optimal Capital Structure. Journal of Business 51, 103-114. 
Byoun, S., 2008. How and When Do Firms Adjust Their Capital Structures toward Targets? Journal of Finance 63, 3069-3096.

Caner, M. and Hansen. B.E., 2004. Instrumental Variable Estimation of a Threshold Model. Econometric Theory 20, 813-843.

Chan, K.S., 1993. Consistency and Limiting Distribution of the Least Squares Estimator of a Threshold Autoregressive Model. Annals of Statistics 21, 520-33.

Chang, X., Dasgupta, S., 2009. Target Behavior and Financing: How Conclusive is the Evidence. Journal of Finance 64, 1767-1796.

Chen, L., Zhao, Z., 2007. Mechanical Mean Reversion of Leverage Ratios. Economic Letters 95, 223-229.

Cook, D.O., Kieschnick, R., McCullough, B.D., 2008. Regression Analysis of Proportions in Finance with Self Selection. Journal of Empirical Finance 15, 860-867.

Dang, V.A., 2011. Leverage, Debt Maturity and Firm Investment: An Empirical Analysis. Journal of Business Finance and Accounting 38, 225-258.

Dang, V.A., Garrett, I., Nguyen, C., 2011. Asymmetric Partial Adjustment toward Target Leverage: International Evidence. Unpublished Manuscript, University of Manchester.

Davies, R.B., 1987. Hypothesis Testing When A Nuisance Parameter Is Present Only under The Alternative. Biometrika 74, 33-43.

DeAngelo, H., Masulis, R., 1980. Optimal Capital Structure under Corporate and Personal Taxation. Journal of Financial Economics 8, 3-29.

Drobetz, W., Wanzenried, G., 2006. What Determines the Speed of Adjustment to The Target Capital Structure?. Applied Financial Economics 16, 941-958.

Drobetz, W., Pensa, P., Wanzenried, G., 2006. Firm Characteristics and Dynamic Capital Structure Adjustment. Unpublished Manuscript, University of Hamburg.

Everaert, G., Pozzi, L., 2007. Bootstrap-based Bias Correction for Dynamic Panels. Journal of Economic Dynamics \& Control 31, 1160-1184.

Fama, E.F., French, K.R., 2002. Testing Trade-Off and Pecking Order Predictions about Dividends and Debt. Review of Financial Studies 15, 1-33.

Faulkender, M.W., Flannery, M.J., Hankins, K.W., Smith, J.M., 2011. Cash Flows and Leverage Adjustments. Journal of Financial Economics, Forthcoming. 
Fischer, E.O., Heinkel, R., Zechner, J., 1989. Dynamic Capital Structure Choice: Theory and Tests. Journal of Finance 44, 19-40.

Flannery, M.J., Hankins, K.W., 2007. A Theory of Capital Structure Adjustment Speed. Unpublished Manuscript, University of Florida.

Flannery, M.J., Rangan, K.P., 2006. Partial Adjustment toward Target Capital Structures. Journal of Financial Economics 79, 469-506.

Frank, M.Z., Goyal, V.K., 2007. Trade-off and Pecking Order Theories of Debt, in Eckbo, B.E. (ed). Handbook of Corporate Finance: Empirical Corporate Finance. North Holland Handbooks of Finance, Elsevier Science.

Hahn, J., Hausman, J., Kuersteiner, G., 2007. Long Difference Instrumental Variables Estimation for Dynamic Panel Models with Fixed Effects. Journal of Econometrics $140,574-617$.

Hansen, B.E., 1996. Inference When A Nuisance Parameter Is Not Identified under The Null Hypothesis, Econometrica 64, 413-430.

Hansen, B.E., 1999. Threshold Effects in Non-dynamic Panels: Estimation, Testing and Inference. Journal of Econometrics 93, 345-368.

Hansen, B.E., 2000. Sample Splitting and Threshold Estimation. Econometrica 68, 575603.

Harris, M., Raviv, A., 1991. The Theory of Capital Structure. Journal of Finance 46, 297-356.

Hennessy, C.A., Whited, T.M., 2006. Debt Dynamics. Journal of Finance 60, 1129-1165.

Hovakimian, A., 2004. The Role of Target Leverage in Security Issues and Repurchases. Journal of Business 77, 1041-1071.

Huang, R., Ritter, J.R., 2009. Testing Theories of Capital Structure and Estimating the Speed of Adjustment. Journal of Financial and Quantitative Analysis 44, 237-271.

Jensen, M., 1986. Agency Costs of Free Cash Flow, Corporate Finance and Takeovers. American Economic Review 76, 323-339.

Kourtellos, A., Stengos, T.S., Tan, C.M., 2009. Structural Threshold Regression. Unpublished manuscript, University of Cyprus, University of Guelph and Tufts University.

Kraus, A., Litzenberger, R.H., 1973. A State-PreferenceTan, C.M., Model of Optimal Financial Leverage. Journal of Finance 28, 911-922. 
Lang, L.E., Ofek, E., Stulz, R., 1996. Leverage, Investment and Firm Growth, Journal of Financial Economics 40, 3-29.

Leary, M.T., Roberts, M.R., 2005. Do Firms Rebalance Their Capital Structures?. Journal of Finance 60, 2575-2619.

Leland, H.E., 1994. Corporate Debt Value, Bond Covenants, and Optimal Capital Structure. Journal of Finance 49, 1213-1252.

Lemmon, M.L., Roberts, M.R., Zender, J.F., 2008. Back to the Beginning: Persistence and the Cross-Section of Corporate Capital Structure. Journal of Finance 63, 15751608.

Modigliani, F., Miller, M.H., 1958, The Cost of Capital, Corporate Finance and the Theory of Investment, American Economic Review 49, 261-297.

Myers, S.C., 1977. Determinants of Corporate Borrowing. Journal of Financial Economics $5,145-175$.

Myers, S.C., 1984. The Capital Structure Puzzle. Journal of Finance 34, 575-592.

Myers, S.C. and Majluf, N.S., 1984. Corporate Fobserve for financing imbalance, investment and inancing and Investments Decisions When Firms Have Information That Investors Do Not Have. Journal of Financial Economics 13, 187-221.

Nickell, S.J., 1981. Biases in Dynamic Models with Fixed Effects. Econometrica 49, 14171426.

Ozkan, A., 2001. Determinants of Capital Structure and Adjustment to Long Run Target: Evidence from UK Company Panel Data. Journal of Business Finance and Accounting 28, 175-198.

Pagan, A., 1984. Econometric Issues in the Analysis of Regressions with Generated Regressors. International Economic Review 25, 221-247.

Politis, D.N., Romanos, J.P., Wolf, M., 1999. Subsampling. Springer Verlag, New York.

Rajan, R.G., Zingales, L., 1995. What Do We Know about Capital Structure? Some Evidence from International Data. Journal of Finance 50, 1421-1461.

Roodman, D., 2009. How to Do xtabond2: An Introduction to Difference and System GMM in Stata? Stata Journal, 9, 86-136

Seo, M.H., Linton, O., 2007. A Smoothed Least Squares Estimator for Threshold Regression Models. Journal of Econometrics 141, 704-735. 
Shyam-Sunder, L., Myers, S., 1999. Testing Static Trade-off against Pecking Order Models of Capital Structure. Journal of Financial Economics 51, 219-244.

Strebulaev, I.A., 2007. Do Tests of Capital Structure Theory Mean What They Say. Journal of Finance 62, 1747-1787.

Titman, S., Tsyplakov, S., 2007. A Dynamic Model of Optimal Capital Structure. Review of Finance 11, 401-451.

Titman, S., Wessels, R., 1988. The Determinants of Capital Structure Choice. Journal of Finance 43, 1-19.

Welch, I., 2004. Capital Structure and Stock Returns. Journal of Political Economy 112, 106-31.

Welch, I., 2007. Common Flaws in Empirical Capital Structure Research, AFA 2008 New Orleans Meetings Paper.

Windmeijer, F., 2005. A Finite Sample Correction for the Variance of Linear Efficient Two-step GMM Estimators. Journal of Econometrics 126, 25-51.

Zilak, J., 1997. Efficient Estimation with Panel Data When Instruments Are Predetermined: An Empirical Comparison of Moment-Condition Estimators. Journal of Business and Economic Statistics 15, 419-431. 
Table 1: Rejection Probability of the Bootstrap-based Wald Test in Dynamic Panel Threshold Models

This table reports the probability of rejecting the null of no threshold effects (one regime) in dynamic panel threshold models by using the bootstrap-based Wald test statistic as described in Section 4.1. The probability is evaluated based on 1,000 replications of regression, (25) (the threshold partial adjustment model) at the $5 \%$ and $1 \%$ significance levels. The coefficients are estimated by the two-step first-difference GMM estimator and the threshold value is estimated through a grid search over the range between the 15 th and 85th percentiles of the transition variable. Simulated data are generated by $(25)$ with the parameters set as follows: $\left(\delta_{1}, \beta_{1}, \rho, \mu_{q}, \sigma_{u}, \sigma_{v}, \kappa\right)=(0.5,1,0.5,0,1,1,3)$ with $T=10$ and $N=(100,200)$. Two forms of variance are considered in (28), namely homoscedasticity $(a=0)$ and heteroscedasticity $(a=0.3)$. The unit long-run variance is set such that $w=1-a$. For each realization of the sample size $(N, T), T+10$ time period observations are generated and then the first 10 observations are discarded. Experimented parameter values are specified in the first column.

\begin{tabular}{rcccccccc}
\hline \hline $\begin{array}{r}\text { Error variance } \\
\text { Significance level }\end{array}$ & \multicolumn{3}{c}{ Homoscedasticity } & \multicolumn{5}{c}{ Heteroscedasticity } \\
Number of observations & 100 & 200 & 100 & 200 & 100 & 200 & 100 & 200 \\
\hline \hline$\left(\delta_{2}, \beta_{2}\right)$ & & \multicolumn{4}{c}{$H_{0}: \phi_{1}=\phi_{2}, \pi_{1}=\pi_{2}$} \\
$(0.2,0.7)$ & 0.991 & 1.000 & 0.971 & 1.000 & 0.987 & 1.000 & 0.963 & 1.000 \\
$(0.3,0.8)$ & 0.885 & 0.995 & 0.773 & 0.973 & 0.901 & 0.988 & 0.809 & 0.969 \\
$(0.4,0.9)$ & 0.422 & 0.678 & 0.261 & 0.514 & 0.449 & 0.708 & 0.265 & 0.547 \\
$(0.5,1.0)$ & 0.043 & 0.053 & 0.016 & 0.019 & 0.055 & 0.058 & 0.019 & 0.020 \\
$(0.6,1.1)$ & 0.356 & 0.633 & 0.194 & 0.469 & 0.325 & 0.627 & 0.166 & 0.474 \\
$(0.7,1.2)$ & 0.792 & 0.965 & 0.650 & 0.907 & 0.801 & 0.956 & 0.648 & 0.926 \\
$(0.8,1.3)$ & 0.960 & 0.998 & 0.890 & 0.993 & 0.938 & 1.000 & 0.869 & 0.996 \\
\hline
\end{tabular}


Table 2: Variable Definitions

This table describes the proxies for the variables considered in the paper. The data set is a panel of UK firms collected from Datastream and consists of 859 companies and 5,393 firm-year observations over the period 1996-2003.

\begin{tabular}{ll}
\hline \hline Variables & Definitions \\
\hline \hline Leverage & Total debt to the market value of equity plus the book value of debt \\
(Asset) Tangibility & Fixed assets to total assets \\
Growth opportunities & The market value of equity plus the book value of debt to total assets \\
Profitability & Earnings Before Interest and Depreciation (EBITD) to total assets \\
Non-debt tax shields & $\begin{array}{l}\text { Depreciation to total assets } \\
\text { Size }\end{array}$ \\
Lnvestment & Capital expenditures less depreciation divided by fixed assets \\
Deviation & Actual leverage less (estimated) target leverage \\
Net debt issued & Net debt issued to the firm's market value \\
Net equity issued & Net equity issued to the firm's market value \\
Financing imbalance & $\begin{array}{l}\text { Minus Cash flow after tax plus Net investment (incl. Capital Expenditures, } \\
\text { Acquisitions and Disposals) plus Dividends plus Net change in cash including } \\
\text { changes in working capital, all divided by the firm's market value }\end{array}$ \\
\hline
\end{tabular}

Table 3: Descriptive Statistics

The data set consists of a panel of 859 UK firms with 5,393 firm-year observations over the period 19962003. To minimize the effects of extreme outliers, we follow the literature and winsorize each variable at the 1st and 99th percentiles. See Table 2 for variable definitions.

\begin{tabular}{lrrrrrrr}
\hline \hline Variables & Mean & Stdev. & Min & Med. & Max & Skew. & Kurt. \\
\hline \hline Leverage & 0.200 & 0.199 & 0.000 & 0.146 & 0.990 & 1.104 & 3.750 \\
Asset tangibility & 0.310 & 0.243 & 0.000 & 0.256 & 0.997 & 0.846 & 2.903 \\
Non-debt tax shields & 0.039 & 0.031 & 0.000 & 0.033 & 0.204 & 1.947 & 8.816 \\
Profitability & 0.014 & 0.266 & -1.495 & 0.079 & 0.446 & -3.213 & 16.255 \\
Growth & 2.043 & 2.216 & 0.188 & 1.363 & 20.000 & 4.556 & 30.326 \\
Size & 11.189 & 2.105 & 1.609 & 11.012 & 18.961 & 0.343 & 3.167 \\
Investment & 0.043 & 0.665 & -3.710 & 0.022 & 3.840 & 0.125 & 23.768 \\
Financing imbalance & 0.024 & 0.143 & -0.690 & 0.001 & 0.645 & 0.296 & 10.049 \\
Net debt issued & -0.005 & 0.097 & -0.540 & -0.001 & 0.358 & -1.167 & 11.891 \\
Net equity issued & 0.054 & 0.169 & -0.175 & 0.001 & 1.133 & 3.926 & 20.030 \\
\hline
\end{tabular}


Table 4: Regression Results for the Partial Adjustment Model of Leverage

This table presents the regression and test results for the one-stage partial adjustment models of leverage given by Equation (3). AH-IV stands for the Anderson-Hsiao just-identified instrumental variable estimator, where leverage lagged by two periods is used as an instrument for the first-difference of leverage lagged by one period. GMM refers to the two-step GMM estimator with Windmeijer's (2005) smallsample correction being applied to the computation of the two-step GMM standard errors. AR(2) test is a test for second-order serial correlation, and is asymptotically distributed as $N(0,1)$ under the null of no serial correlation. Sargan test is a test for the validity of instruments and is asymptotically distributed as $\chi^{2}$ under the null of valid instruments. Figures in () are the standard errors of the coefficients and those in [] are the p-values of the test statistics. All coefficients are significant at the $1 \%$ level. See also Table 2 for variable definitions. All computations are carried out using Stata; the AH-IV and GMM estimates are obtained using Stata module xtabond2 (Roodman, 2009), which is non-commercially downloadable through Statistical Software Components (SSC). All program modules available upon request.

\begin{tabular}{lccc}
\hline \hline $\begin{array}{l}\text { Independent } \\
\text { variables }\end{array}$ & $\begin{array}{c}\text { Expected } \\
\text { Sign }\end{array}$ & \multicolumn{2}{c}{ Partial Adjustment Model } \\
\hline \hline Panel A. Short-run dynamics & & AH-IV & GMM \\
Leverage (t-1) & + & 0.470 & 0.403 \\
& & $(0.068)$ & $(0.074)$ \\
Tangibility (t) & 0.241 & 0.231 \\
& & $(0.049)$ & $(0.050)$ \\
Non-debt tax shields (t) & -0.649 & -0.549 \\
& $(0.225)$ & $(0.225)$ \\
Profitability (t) & -0.124 & -0.115 \\
& $(0.017)$ & $(0.017)$ \\
Growth opportunities (t) & -0.009 & -0.008 \\
& $(0.002)$ & $(0.002)$ \\
Size (t) & 0.050 & 0.051 \\
& & $(0.009)$ & $(0.009)$ \\
Speed of adjustment & 0.530 & 0.597 \\
Number of observations & 3673 & 3673 \\
Time dummies & Yes & Yes \\
AR(2) test & $-1.48[0.14]$ & $-1.51[0.13]$ \\
Sargan test & & $23.82[0.25]$ \\
\hline \hline
\end{tabular}

\begin{tabular}{llrr}
\hline \hline Panel B. Long-run coefficients & & & \\
Tangibility (t) & + & 0.455 & 0.387 \\
& & $(0.116)$ & $(0.099)$ \\
Non-debt tax shields (t) & $-/+$ & -1.224 & -0.920 \\
& & $(0.506)$ & $(0.433)$ \\
Profitability (t) & $+/-$ & -0.234 & -0.193 \\
& & $(0.046)$ & $(0.038)$ \\
Growth opportunities (t) & - & -0.017 & -0.014 \\
& & $(0.004)$ & $(0.004)$ \\
Size (t) & + & 0.095 & 0.086 \\
& & $(0.021)$ & $(0.018)$ \\
\hline
\end{tabular}




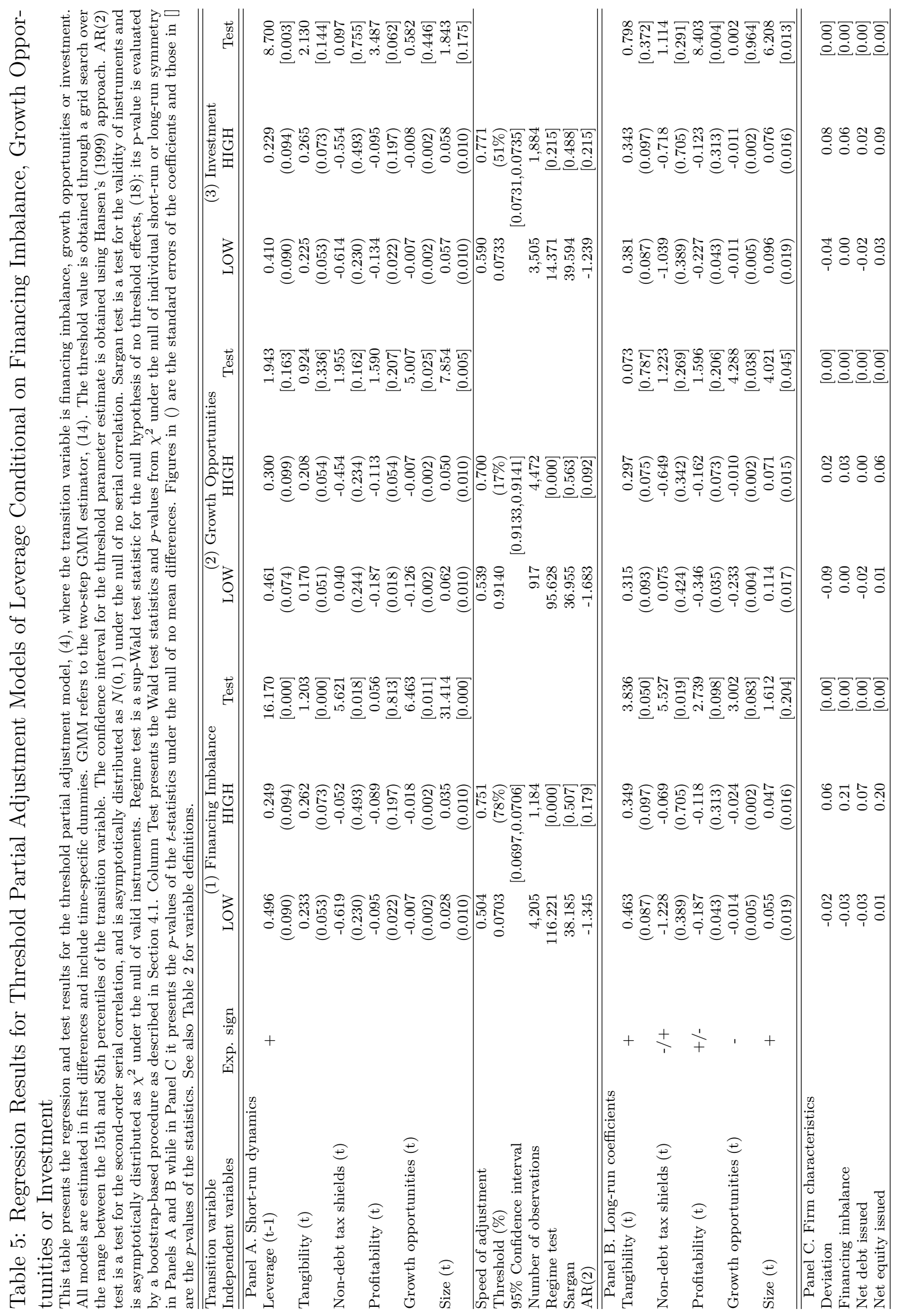




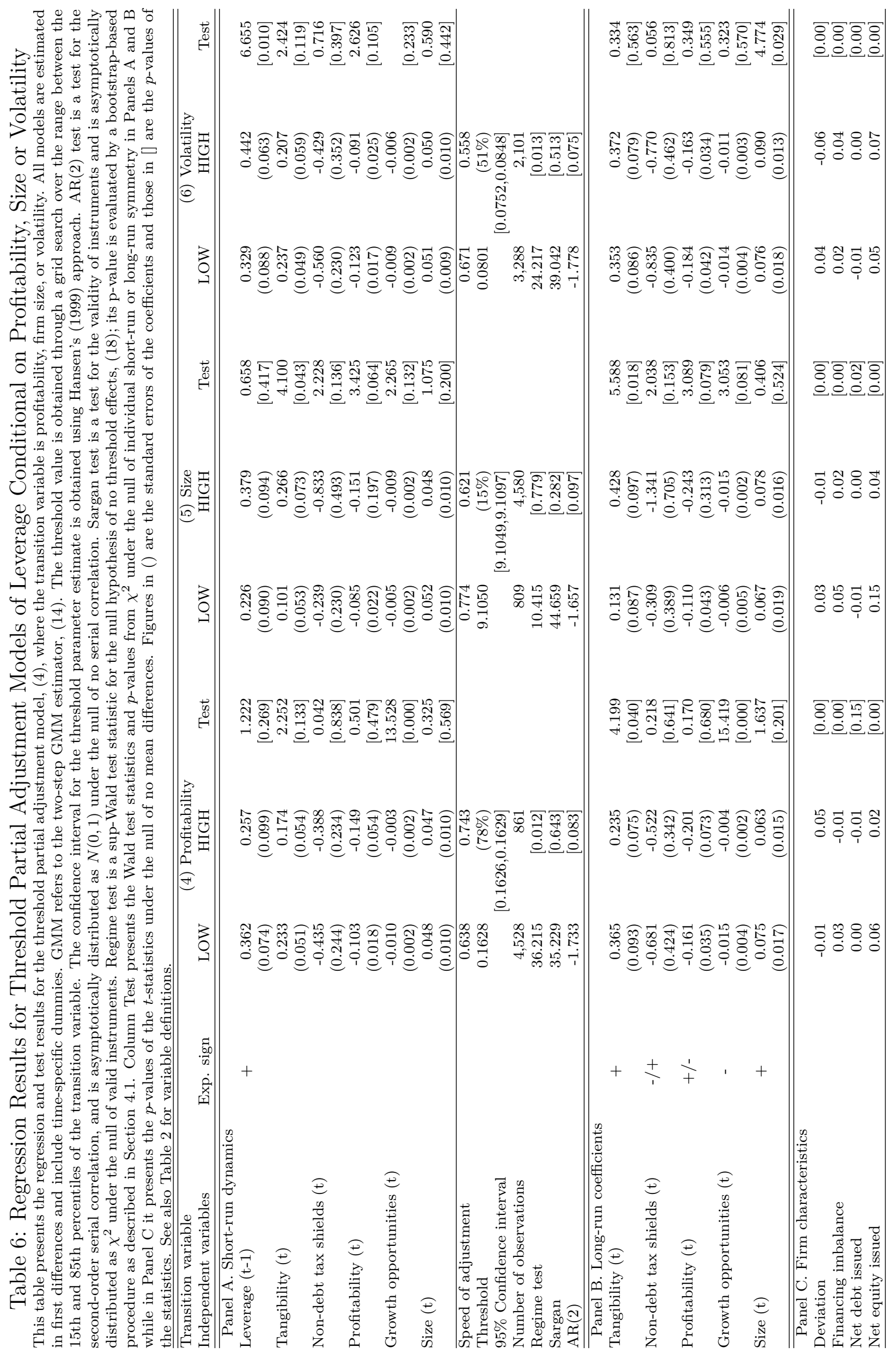

